\title{
AN INVESTIGATION OF PENETRANT TECHNIQUES FOR DETECTION OF MACHINING-INDUCED SURFACE-BREAKING CRACKS \\ ON MONOLITHIC CERAMICS
}

G. A. Forster and W. A. Ellingson

Date Published: February 1996

Prepared by Argonne National Laboratory Energy Technology Division 9700 Cass Avenue Argonne, Illinois 60439

Funded by

Propulsion System Materials Program

Office of Transportation Technologies

the Assistant Secretary for Energy Efficiency and Renewable Energy

U.S. Department of Energy

EE 51050000

\author{
for \\ OAK RIDGE NATIONAL LABORATORY \\ Oak Ridge, Tennessee 37831 \\ managed by \\ LOCKHEED MARTIN ENERGY RESEARCH CORPORATION \\ for the \\ U.S. DEPARTMENT OF ENERGY \\ under contract DE-AC05-96OR22464




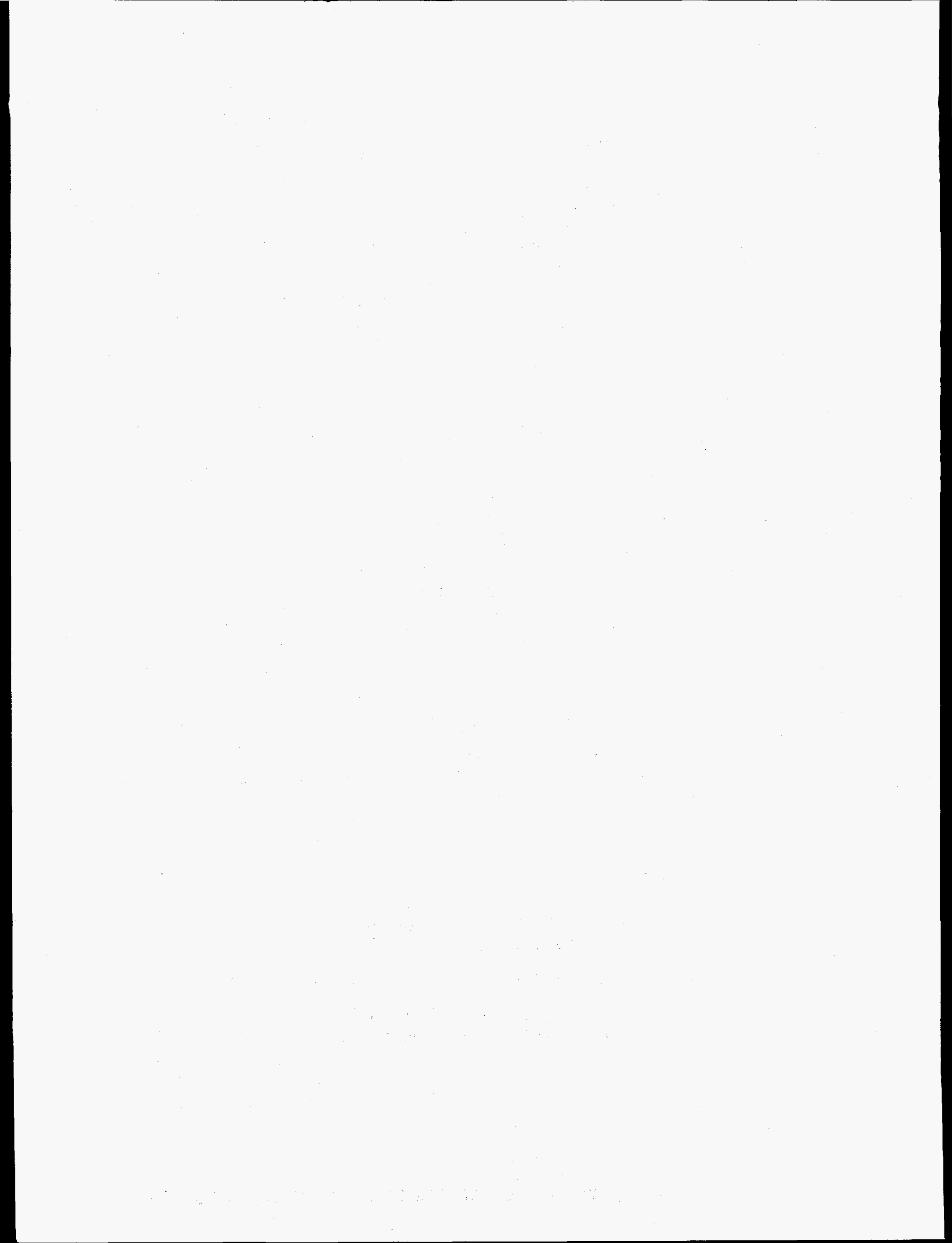




\section{DISCLAIMER}

Portions of this document may be illegible in electronic image products. Images are produced from the best available original document. 



\section{DISCLAIMER}

This report was prepared as an account of work sponsored by an agency of the United States Government. Neither the United States Government nor any agency thereof, nor any of their employees, makes any warranty, express or implied, or assumes any legal liability or responsibility for the accuracy, completeness, or usefulness of any information, apparatus, product, or process disclosed, or represents that its use would not infringe privately owned rights. Reference herein to any specific commercial product, process, or service by trade name, trademark, manufacturer, or otherwise does not necessarily constitute or imply its endorsement, recommendation, or favoring by the United States Government or any agency thereof. The views and opinions of authors expressed herein do not necessarily state or reflect those of the United States Government or any agency thereof. 

Table of Contents

Topic

Abstract v

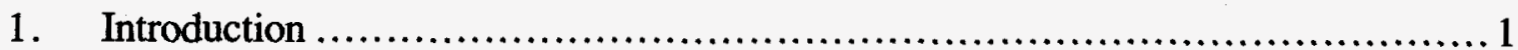

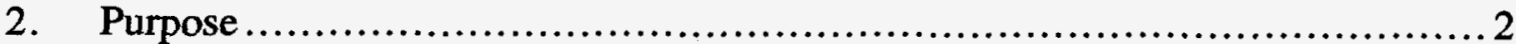

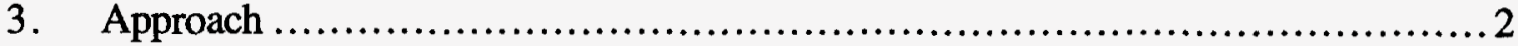

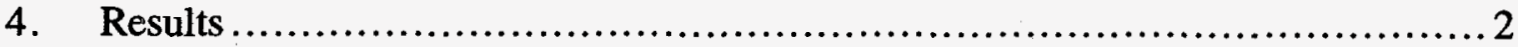

a. Literature Review ..................................................... 2

b. Experimental Results ................................................. 3

Part 1: Gaseous diffusion, Charged Particle, and Visible Dye.................. 3

Part 2: Fluorescent Penetrants ............................................. 7

5. Recommendations .........................................................

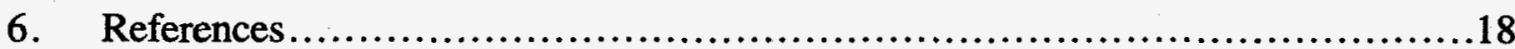

Appendix A. Product Sheets.................................................21

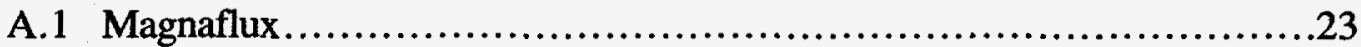

A.2 Sherwin..........................................................

Apendix B. List of Dye Penetrant Suppliers.................................43 



\section{Abstract}

The purpose of this effort was to evaluate penetrant methods for their ability to detect surface-breaking cracks in monolithic ceramic materials with an emphasis on detection of cracks generated by machining. There are two basic penetrant types, visible and fluorescent. The visible penetrant method is usually augmented by powder developers and cracks detected can be seen in visible light. Cracks detected by fluorescent penetrant are visible only under ultraviolet light used with or without a developer. The developer is basically a powder that wicks up penetrant from a crack to make it more observable.

Although fluorescent penetrants were recommended in the literature survey conducted early in this effort, visible penetrants and two non-standard techniques, a capillary gaseous diffusion method under development at the institute of Chemical Physics in Moscow, and the "statiflux" method which involves use of electrically charged particles, were also investigated. SiAlON ring specimens (1 in. diameter, $3 / 4$ in. wide) which had been subjected to different thermal-shock cycles were used for these tests.

The capillary gaseous diffusion method is based on ammonia; the detector is a specially impregnated paper much like litmus paper. Advantages of this method were low after-test residuals and low environmental impact, while disadvantages included poor resolution power and poor-shape adaptability of the paper detector. As expected, visible dye penetrants offered no detection sensitivity for tight, surfacebreaking cracks in ceramics. Although the non-standard statiflux method showed promise on high-crack-density specimens, it was ineffective on limited-crackdensity specimens. The fluorescent penetrant method was superior for surfacebreaking crack detection, but successful application of this procedure depends greatly on the skill of the user. Two presently available high-sensitivity fluorescent penetrants were then evaluated for detection of microcracks on $\mathrm{Si}_{3} \mathrm{~N}_{4}$ and $\mathrm{SiC}_{\text {from }}$ different suppliers. Although $50 \mathrm{X}$ optical magnification may be sufficient for many applications, 200X magnification provides excellent detectability.

Research sponsored by the U.S. Department of Energy, Assistant Secretary for Energy Efficiency and Renewable Energy, Office of Transportation Technologies, as part of the Ceramic Technology Project of the Propulsion Systems Materials Program, under contract DE-AC05-960R22464 with Lockheed Martin Energy Research Corporation. 


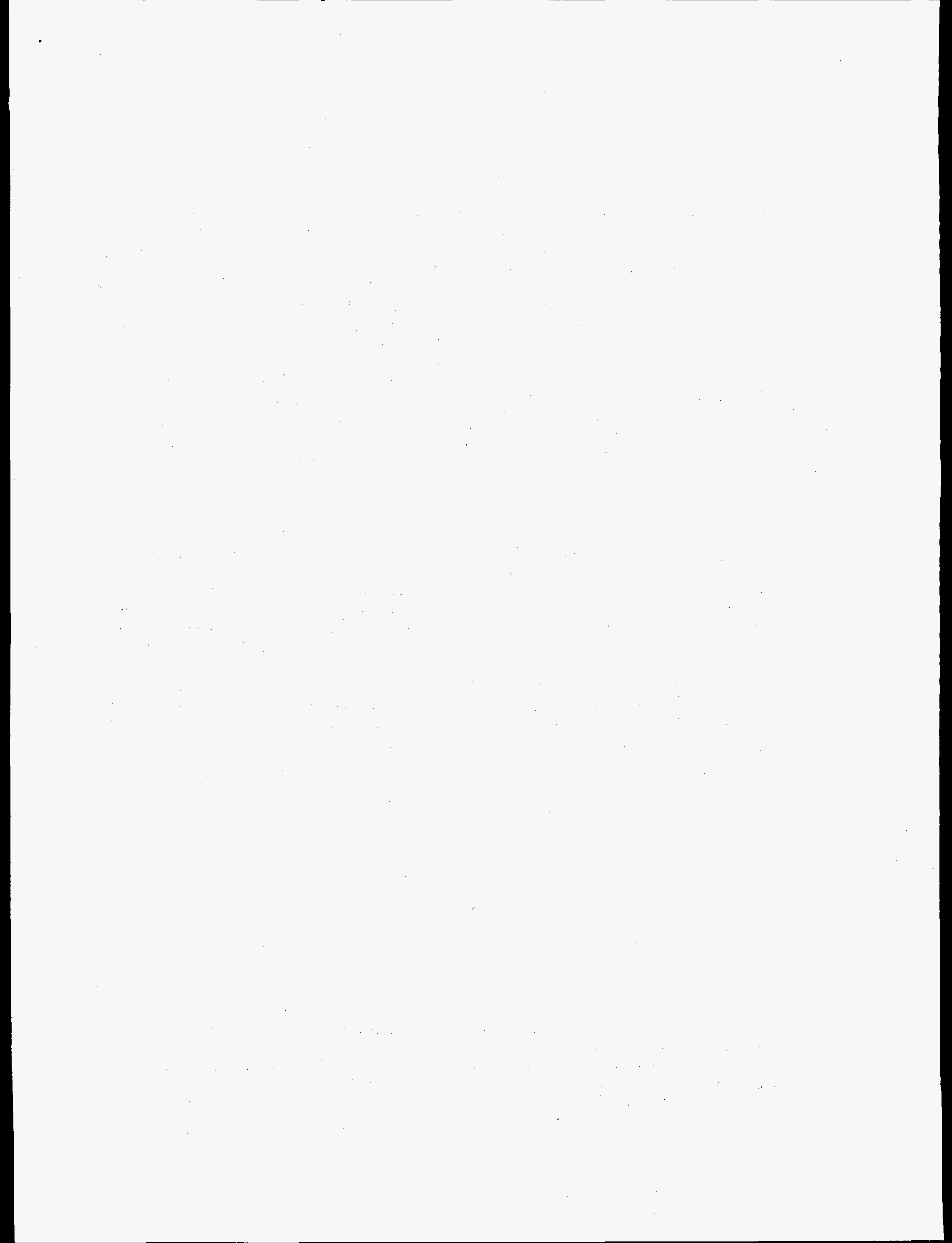


An Investigation of Penetrant Techniques for Detection of Machining Induced Surface-Breaking Cracks on Monolithic Ceramics

by

G. A. Forster and W. A. Ellingson

\section{Introduction}

Detection of surface breaking cracks by low-cost penetrant methods has been an accepted nondestructive evaluation method for use on metal for many years and has been shown to be especially useful for defect detection on castings and weldments. Application of penetrants to ceramic components is relatively new. The American Society for Testing Materials (ASTM) developed a penetrant standard, E165-91 covering generalized penetrant test methods. This is supplemented by other standards that cover specific penetrants and methods. These standards have also been adopted by the American Society of Mechanical Engineers (ASME). However, standard E165-91 specifically does not address environmental or other safety problems related to the use of any materials or solvents, leaving that responsibility to the user. There are many penetrant methodologies available, but there are two basic penetrant types, visible and fluorescent. However, recent work $(1,2)$ has suggested that fluorescent penetrants are best for ceramics.

The visible penetrant method usually is augmented by powder developers and cracks detected can be seen in visible light. Cracks detected by fluorescent penetrant are visible only under stimulation by ultraviolet light. Flourescent penetrant is used with or without a developer. The developer is basically a powder that wicks up penetrant from a crack to make it more observable.

Although fluorescent penetrants had been recommended in the literature, we briefly assessed visible penetrants as well as two unconventional crack detection "penetrant" methods. The two unconventional methods were: (a) "Statiflux", a method using a statically charged powder which adheres to cracks where there is a disruption of dielectric field and (b) a gaseous diffusion method under development in Russia wherein a gas (ammonia) diffuses into cracks and a detector utilizing treated paper is laid over the surface and changes color in 
response to the gas coming from the cracks leaving a mirror image of any crack pattern.

\section{Purpose}

The purpose of this project was to evaluate penetrant methods for their ability to detect surface-breaking cracks in monolithic ceramic materials with an emphasis on detection of cracks generated by machining.

\section{Approach}

The approach used in this project was to first review the available literature and contact domestic ceramics suppliers to obtain the current status of penetrant application from their point of view. We also contacted manufacturers of dye penetrants and related materials. The second step was to conduct laboratory investigations to assess current approaches and to perhaps provide a direction for continued study should the results show promise.

\section{Results}

\section{a. Literature Review}

A review of the literature showed that there had been only limited publication on use of penetrants for ceramics materials. The most applicable and promising was the work of Horton (1), who demonstrated that use of fluorescent penetrants on highly polished ceramic ball bearings could detect critical cracks for rolling contact fatigue applications. What this work suggested was the apparent need for optical magnification when examining ceramics using fluorescent penetrants. All work here was on highly polished surfaces with surface finishes of $\mathrm{Ra}<.5 \mu \mathrm{m}$. Kölker, et al. (2), suggested that fluorescent penetrants could detect cracks with less than $0.1 \mu \mathrm{m}$ opening and further, that these applications could be made on "green" bodies although "green" conditions were not specified. In 1993, Maling et al. (3), published an article which illuminated the concerns about environmental issues related to disposal of penetrants. Fluorescent penetrants use halocarbons (e.g., trichloroethylene) and the renewal of the Clean Air Act, the Clean Water Act and the Resources Conservation and Recovery Act 
caused focus on the environmental "unfriendliness" of these halocarbons. Table 1 shows the environmental concerns as a function of the steps in the penetrant process and what is currently under study.

We also conducted a limited telephone survey. In this survey, ceramic component manufacturers indicated that they use fluorescent penetrant inspection (FPI) of their products on a routine basis. The materials and procedures used were considered proprietary. They also said they were addressing problem chemicals such as trichlorethylene in their procedures.

\section{b. Experimental Results}

Part 1: Gaseous diffusion, Charged Particle, and Visible Dye

Our exploratory effort to evaluate penetrant technologies included two non-standard techniques. These non-standard techniques were: (a) a capillary gaseous diffusion method (4) being developed at the Institute of Chemical Physics in Moscow, Russia, and (b) a charged particle method which involves use of electrically charged particles. This is a product produced by Stresscoat, Inc., of Upland, California.

\section{Capillary Gaseous Diffusion}

Very tight surface-breaking cracks in ceramics may be detectable by use of an appropriate gas instead of a liquid. Recently, a capillary gaseous diffusion method based on ammonia has been described by Marotta Scientific (4). In this method, a part under study is placed in a chamber with an environment containing gaseous ammonia. The overpressure is low, $\approx 0.1 \mathrm{~atm}$. The "soak" time is dependent upon the part. The detector currently is a special impregnated paper similar in many respects to litmus paper. The rigidity of the paper detector limits the usefulness as complex contours cannot be followed by the "felt-like" paper detector. This method was studied at Argonne and the Russian scientists developing this technology visited Argonne and spent 2 days running tests. The obvious advantages are: a) low after-test residuals and b) low environmental impact. The current disadvantages are: a) the 


\section{Table 1. Environmental Issues in FPT Processes (from Malins et al.)}

\begin{tabular}{|c|c|c|c|}
\hline $\begin{array}{l}\text { FPT Process } \\
\text { Station }\end{array}$ & $\begin{array}{c}\text { Environmental Issues in } \\
\text { Conventional } \\
\text { Implementations }\end{array}$ & $\begin{array}{c}\text { Environmental } \\
\text { Improvement Approaches }\end{array}$ & $\begin{array}{l}\text { Residual Environmental } \\
\text { Issues }\end{array}$ \\
\hline $\begin{array}{l}\text { Station 1: } \\
\text { Part Cleaning }\end{array}$ & $\begin{array}{l}\text { - Degreaser solvent wastes } \\
\text { (organic or halocarbon } \\
\text { solvents); health, safety, } \\
\text { and environmental } \\
\text { aspects of solvent vapor } \\
\text { escape. } \\
\text { - Sludge, grease, coating } \\
\text { debris removed from part } \\
\text { (dispersed in degreaser } \\
\text { solvent). }\end{array}$ & $\begin{array}{l}\text { Convert to non-solvent } \\
\text { based cleaning and- } \\
\text { degreasing process such } \\
\text { as steam cleaning or } \\
\text { supercritical fluid } \\
\text { cleaning (eliminates } \\
\text { issues with solvent waste } \\
\text { and solvent vapor escape). }\end{array}$ & $\begin{array}{l}\text { Will stlll produce some } \\
\text { form of aqueous-based } \\
\text { oll or grease waste } \\
\text { stream for treatment } \\
\text { even if wash liquids (e.g.. } \\
\text { water for steam) are } \\
\text { treated/recycled. }\end{array}$ \\
\hline $\begin{array}{l}\text { Station 2: } \\
\text { Dye Applications }\end{array}$ & $\begin{array}{l}\text { - Waste organic solvent } \\
\text { from dye solution: health, } \\
\text { safety, and environmental } \\
\text { aspects of solvent vapor } \\
\text { escape. } \\
\text { - Toxic (possibly } \\
\text { carcinogenic) dye } \\
\text { compound (concentrated } \\
\text { form and in solvent). }\end{array}$ & $\begin{array}{l}\text { For high sensitivity, } \\
\text { probably cannot } \\
\text { eliminate organic } \\
\text { solvents. However, system } \\
\text { can be changed to more } \\
\text { benign solvents and } \\
\text { equipment design can be } \\
\text { adjusted to minimize } \\
\text { vapor escape. Recycling } \\
\text { solvent can limit waste } \\
\text { output. }\end{array}$ & $\begin{array}{l}\text { Dye will eventually } \\
\text { degrade to point where it } \\
\text { must be removed; with } \\
\text { solvent recycling, volume } \\
\text { can be mintmized. }\end{array}$ \\
\hline $\begin{array}{l}\text { Station 3: } \\
\text { Dye Rinsing }\end{array}$ & $\begin{array}{l}\text { - Rinse water } \\
\text { contaminated with } \\
\text { organic solvent. } \\
\text { - Rinse water } \\
\text { contaminated with toxic } \\
\text { (possibly carcinogenic) } \\
\text { dye compound. }\end{array}$ & $\begin{array}{l}\text { Equipment design can be } \\
\text { optimized to minimize the } \\
\text { volume of rinse water } \\
\text { required: rinse water can } \\
\text { be treated/recycled to } \\
\text { minimize volume fluid } \\
\text { requiring disposal. }\end{array}$ & $\begin{array}{l}\text { Some amount of organic } \\
\text { contaminated waste } \\
\text { water will require } \\
\text { disposal even with } \\
\text { treatment or recycling. }\end{array}$ \\
\hline $\begin{array}{l}\text { Station 4: } \\
\text { Emulsifier } \\
\text { Application }\end{array}$ & $\begin{array}{l}\text { - Used/aged emulsifier } \\
\text { solution (surface } \\
\text { penetrant in water } \\
\text { - Wash water } \\
\text { contaminated with } \\
\text { emulsion of dye, dye } \\
\text { solvent. }\end{array}$ & $\begin{array}{l}\text { Switch completely to } \\
\text { aqueous systems to } \\
\text { eliminate solvents and } \\
\text { minlmize organics in rinse } \\
\text { output: treat/recycle wash } \\
\text { water to minimize volume } \\
\text { requiring disposal. }\end{array}$ & $\begin{array}{l}\text { Some amount of organic } \\
\text { contaminated waste } \\
\text { water will require } \\
\text { disposal even with } \\
\text { treatment or recycling. }\end{array}$ \\
\hline $\begin{array}{l}\text { Station } 5: \\
\text { Developer } \\
\text { Application }\end{array}$ & $\begin{array}{l}\text { Used/aged developer } \\
\text { solution/dispersion } \\
\text { (possibly made of an } \\
\text { organic solvent) } \\
\text { - Biocides in developer } \\
\text { solution/dispersion. }\end{array}$ & $\begin{array}{l}\text { Switch to water-based } \\
\text { developer dispersions (or } \\
\text { to dry developers); convert } \\
\text { to biocides that degrade or } \\
\text { can be removed during } \\
\text { waste treatment. }\end{array}$ & $\begin{array}{l}\text { Some amount of organtc } \\
\text { contaminated waste } \\
\text { water will require } \\
\text { disposal even with } \\
\text { treatment or recycling. }\end{array}$ \\
\hline $\begin{array}{l}\text { Station } 6: \\
\text { Flaw Detection }\end{array}$ & $\begin{array}{l}\text { (Health and safety issues } \\
\text { but no effluent } \\
\text { environmental issues). }\end{array}$ & NA & $\mathrm{NA}$ \\
\hline $\begin{array}{l}\text { Station 7: } \\
\text { Part Cleaning }\end{array}$ & $\begin{array}{l}\text { Possibly organic or } \\
\text { halocarbon wash solvent } \\
\text { for removing developer } \\
\text { and dye. } \\
\text { - Rinse water } \\
\text { contaminated with } \\
\text { developer and dye/dye } \\
\text { solvent. } \\
\text { - Possible health, safety, } \\
\text { environmental issues of } \\
\text { cleaning solution vapors. }\end{array}$ & $\begin{array}{l}\text { Convert to non-solvent } \\
\text { based cleaning and } \\
\text { degreasing process such } \\
\text { as steam cleaning or } \\
\text { supercritical fluid } \\
\text { cleaning (eliminates } \\
\text { issues with solvent waste } \\
\text { and solvent vapor escape). }\end{array}$ & $\begin{array}{l}\text { Will still produce some } \\
\text { form of aqueous based oll } \\
\text { or grease waste stream } \\
\text { for treatment even If } \\
\text { wash liquids (e.g. water } \\
\text { for steam) are } \\
\text { treated/recycled. }\end{array}$ \\
\hline
\end{tabular}


poor resolving power of the detector as the up-take of ammonia in the detector spreads giving a false crack width and $b$ ) the poor shape adaptability of the paper detector.

\section{Charged Particle}

A method previously explored several years ago by one of the investigators (G. Forster) for application to glass insulators, is a method called "Statiflux." In this method, electrostatically charged power is deposited on a non-conducting specimen and the charged particles tend to cluster at crack lines on the surfaces. This method was tested but soon eliminated because of poor detection on simulated crack specimens. The particle sizes were too large for the crack sizes under study.

\section{Visible Dye}

Just to check the reported poor detection of visible dye technology, an exploratory test was conducted. Indeed visible dye penetrants offer no detection sensitivity for tight surface breaking cracks in ceramics.

\section{Test Specimens}

The comparison of these test methods was done using a set of four $25 \mathrm{~mm}$ diameter, $18 \mathrm{~mm}$ wide SiAlON ring specimens which had been subjected to different thermal shock cycles: $0,1,2,3$ thermal shocks with the tests being done at $600^{\circ} \mathrm{C}$ using water as the quench.

The results of comparing crack detection of these three methods is shown in Fig. 1 where the same segment of the surface of one specimen is shown. From these results, statiflux was shown to have the superior detection based on visual observation. However, application of fluorescent penetrant on the same specimen gives the results shown in Fig. 2 which clearly provides sharper and better spatial definition. 

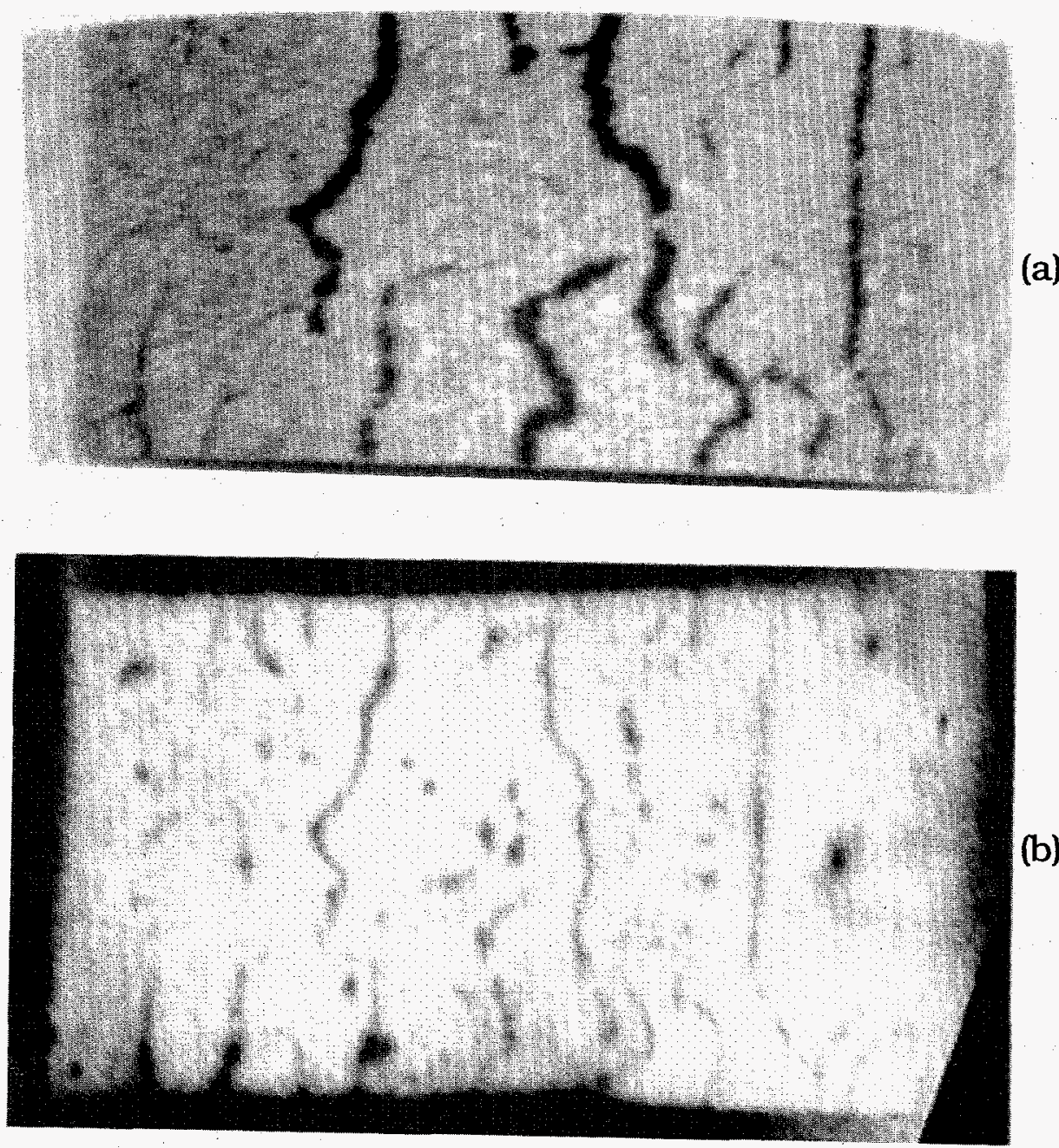

(b)

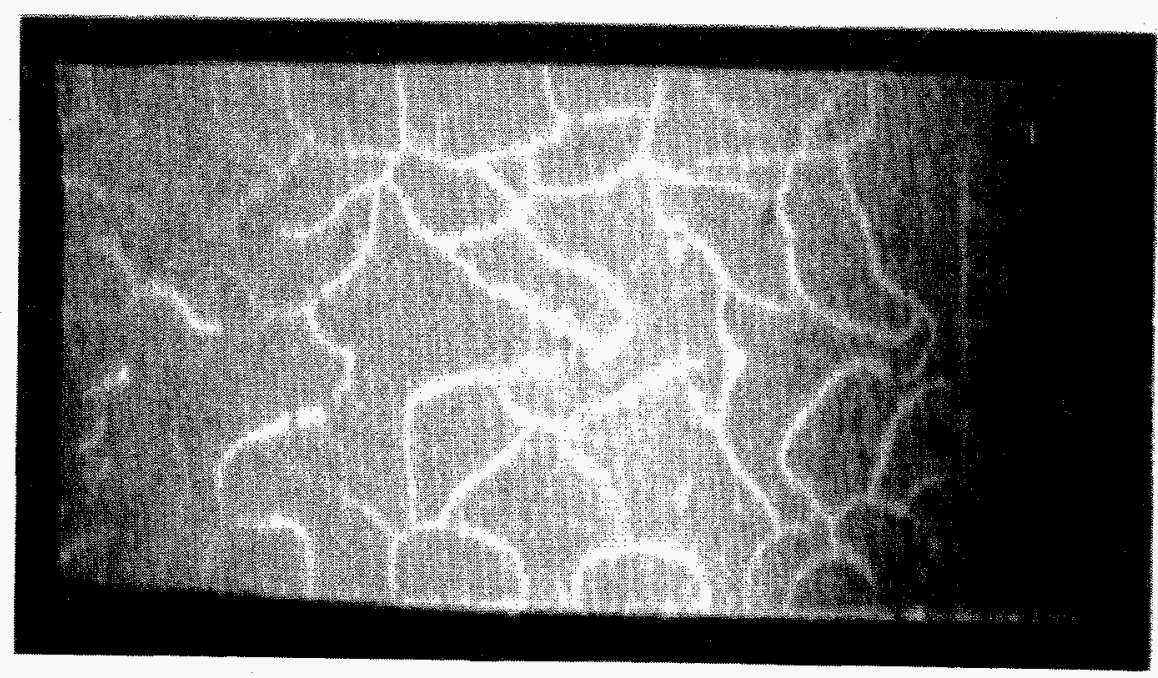

(c)

Fig. 1. Comparison of dye penetrant methods. (a) visible dye penetrant, (b) gaseous diffusion and (c) statiflux, on the same piece of SiAlON $25 \mathrm{~mm}$ dia $\times 18 \mathrm{~mm}$ long. 


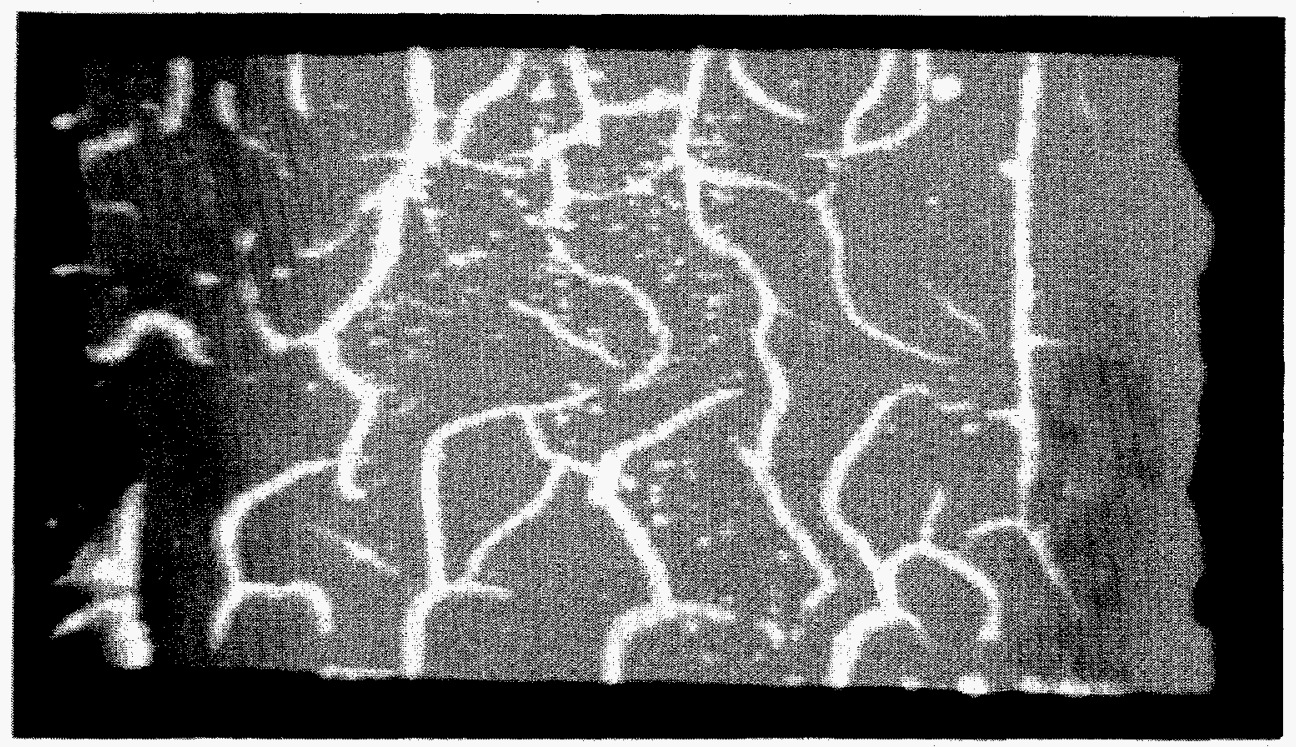

Fig. 2. Same sample as in Fig. 1 but treated with fluorescent penetrant.

\section{Part 2: Fluorescent Penetrants}

The statiflux method, although promising on specimens with a network of cracks soon was shown to be ineffective when used on specimens with limited cracks. SiALON specimens were indented using a microhardness Vicker's indentor to produce specimens with few cracks. Figure 3 shows an optical photo micrograph of a crack emanating from one corner of the indent. The statiflux method did not detect this crack at all whereas fluorescent penetrant easily detected cracks of this size (see Fig. 5). 


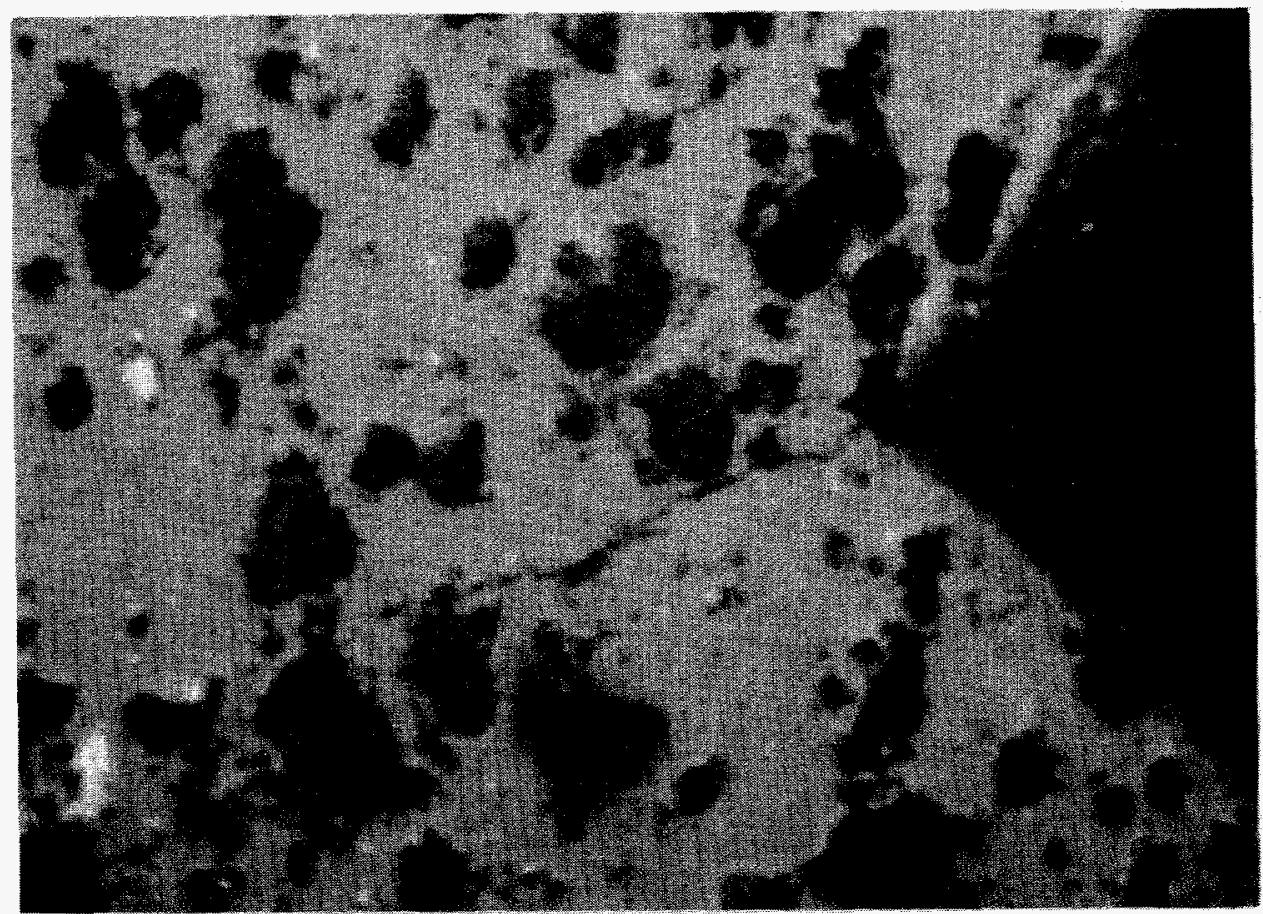

Fig. 3. Partial image of a Vicker's microhardness indent in SiAlON with a microcrack growing from the indent corner. The horizontal field of view is $\sim 125 \mu \mathrm{m}$.

After the fluorescent penetrant method was verified for superior surface-breaking crack detection, a systemmatic study was conducted to evaluate two representative high sensitivity fluorescent penetrants; 1) RC-88 from Sherwin, Inc. and 2) ZL-37 from Magnaflux. a)

These manufacturers produce a general line of dye penetrant inspection materials. Both companies produce a highly penetrating fluorescent dye and a water based emulsifier. We tested materials from both as representative of all suppliers.

Material Safety Data Sheets for the materials indicate that they are non-toxic, slightly irritating to skin and eyes, and are safe when handled in a contolled environment (see Appendix A).

The basic procedures for fluorescent penetrant crack detection is as follows:

a) Other suppliers of dye penetrants are listed in Appendix B. 
1. Clean the specimen.

2. Apply penetrant to the surface.

3. Allow penetrant to soak for a specified time (e.g., 10 minutes min.).

4. Remove excess penetrant from the surface with a suitable cleaner.

5. Apply ultraviolet (UV) light.

6. Visually scan surface for flaws with UV illumination using visual aids as appropriate.

Successful application of a procedure depends to a great extent on the skill of the user. For example, in Step 4, the removal technique must remove excess residual surface penetrant, but not remove penetrant from cracks. During inspection, the user must use judgment guided by experience as to what constitutes acceptable and unacceptable flaws.

As part of this study, we set up a penetrant laboratory (see Fig. 4) with venthood for venting the gases. We also modified an existing Nikon Optiphot Microscope (25-400X) with two additions: a) a special Hg-arc lamp and optical filter combination to allow UV illumination and b) a 512 $\times 480 \times 8$ bit CCD camera coupled to a computer with frame-grabber digitizer board. This allowed high magnification imaging and subsequent digital image archiving as well as digital image processing.

\section{Test Specimens}

Samples for microcrack studies using the two penetrants are listed in Table 2. The samples were identified by Roman numeral serial numbers because these could be scribed on the edges of the samples using a diamond marker. 

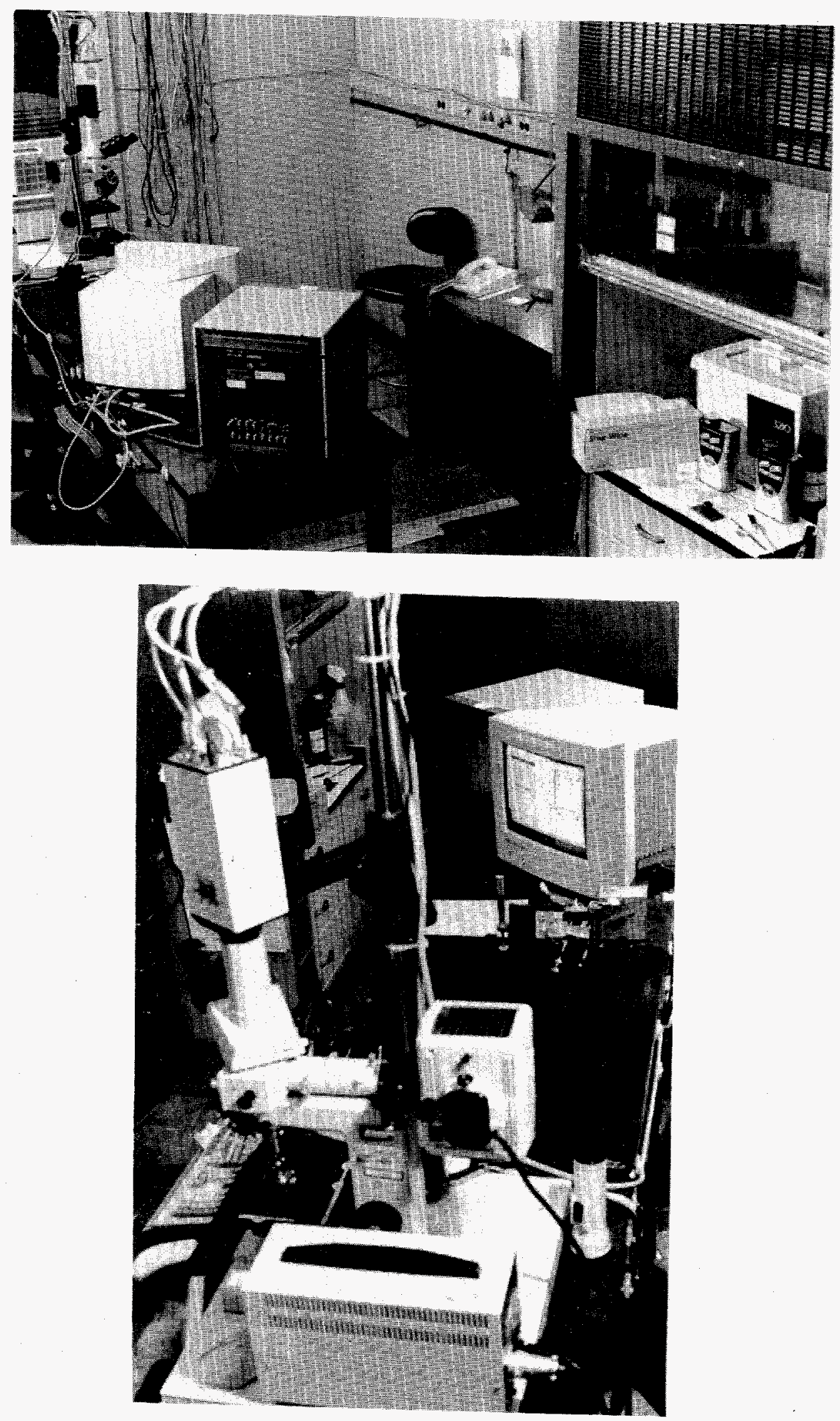

Fig. 4. Photographs of the dye penetrant laboratory. 


\section{Procedures}

The samples were first all ultrasonically cleaned with a biodegradable detergent (ALCONOX) in water and air dried by an air blower. Intentional cracks were then formed by indenting with a Vicker's microhardness indentor. The first indents were made at $20 \mathrm{~kg}$ on SiAlON. Indents made on silicon carbide $(\mathrm{SiC})$ or silicon nitride $\left(\mathrm{Si}_{3} \mathrm{~N}_{4}\right)$ at $20 \mathrm{~kg}$ showed crushing at the edges of the indent. This made measurement of crack lengths difficult. The indent load was reduced to $5 \mathrm{~kg}$ and indent edges still were crushed. We compromised and set the load at $10 \mathrm{~kg}$ for reasonable crack lengths and the cracks were measured from tip to tip across the indent.

Table 2. Test Samples

\begin{tabular}{|c|c|c|c|}
\hline $\begin{array}{l}\text { Sample } \\
\text { Number }\end{array}$ & Material & Sample Size & Supplier \\
\hline \multicolumn{4}{|c|}{-- Silicon Carbide -- } \\
\hline I & NT 230 & $3 \times 4 \times 27 \mathrm{~mm}$ & Norton Advanced Ceramics \\
\hline II & $"$ & $3 \times 4 \times 30$ & “ \\
\hline IIII & Hexaloy SA & $3 \times 4 \times 50$ & Carborundum \\
\hline IV & “ & $3 \times 4 \times 50$ & “ \\
\hline \multicolumn{4}{|c|}{-- Silicon Nitride -- } \\
\hline $\mathrm{V}$ & SN 253 & $3 \times 4 \times 26$ & Kyocera \\
\hline $\mathrm{VI}$ & “ & $3 \times 4 \times 22$ & “ \\
\hline VII & GN 10 & $3 \times 4 \times 25$ & $\begin{array}{l}\text { Allied Signal Ceramic } \\
\text { Components }\end{array}$ \\
\hline VIII & “ & $3 \times 4 \times 25$ & “ \\
\hline $\mathrm{IX}$ & NT 164 & $3 \times 4 \times 50$ & Norton Advanced Ceramics \\
\hline $\mathrm{X}$ & “ & $3 \times 4 \times 50$ & - \\
\hline $\mathrm{XI}$ & SN 88 & $4 \times 6 \times 45$ & NGK \\
\hline
\end{tabular}

The procedure for penetrant application with both penetrants was identical. After indenting, no cleaning was necessary because the cracks had been made on a clean surface and had not been exposed to contaminants. The specific procedure we followed was: 
1. Brush or dip on penetrant and allow to stand for at least ten minutes.

2. Rinse in running tap water for one minute.

3. Dip in emulsifier solution and slowly agitate for one minute.

4. Rinse in running tap water, one minute.

5. Air dry surface at about $100^{\circ} \mathrm{F}$ with clean air until surface appears dry.

6. Inspect under microscope with UV light within 1 to $2 \mathrm{hrs}$ as the fluorescence decays with time.

In Steps 2 and 4 the one minute is approximate and may be reduced for simple shapes. In step 3 the timing is more critical and is dependent on the strength of the remover solution. The one minute time is recommended by both suppliers when using their emulsifier at recommended strength. Too short a time in the emulsifier will leave a film of penetrant on surfaces. A glow from this film during inspection will be an indication to either increase the time or to check the concentration of the emulsifier. Too long a time in the emulsifier will begin to remove penetrant from cracks and reduce the detection sensitivity.

Figure 5 show the results of following this procedure on an indent on sample XI.

Since the purpose of this work was to detect cracks on machined specimens, each specimen was measured for surface roughness using a Rank-Taylor-Hobson Talysurf equipped with a wedge stylus. The surface data are given in Table 3. 


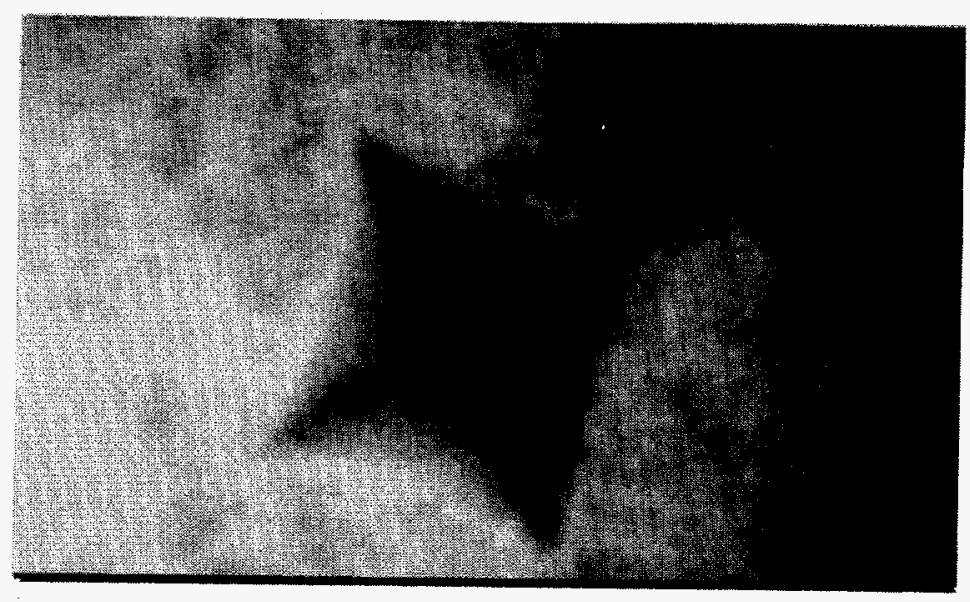

(a)

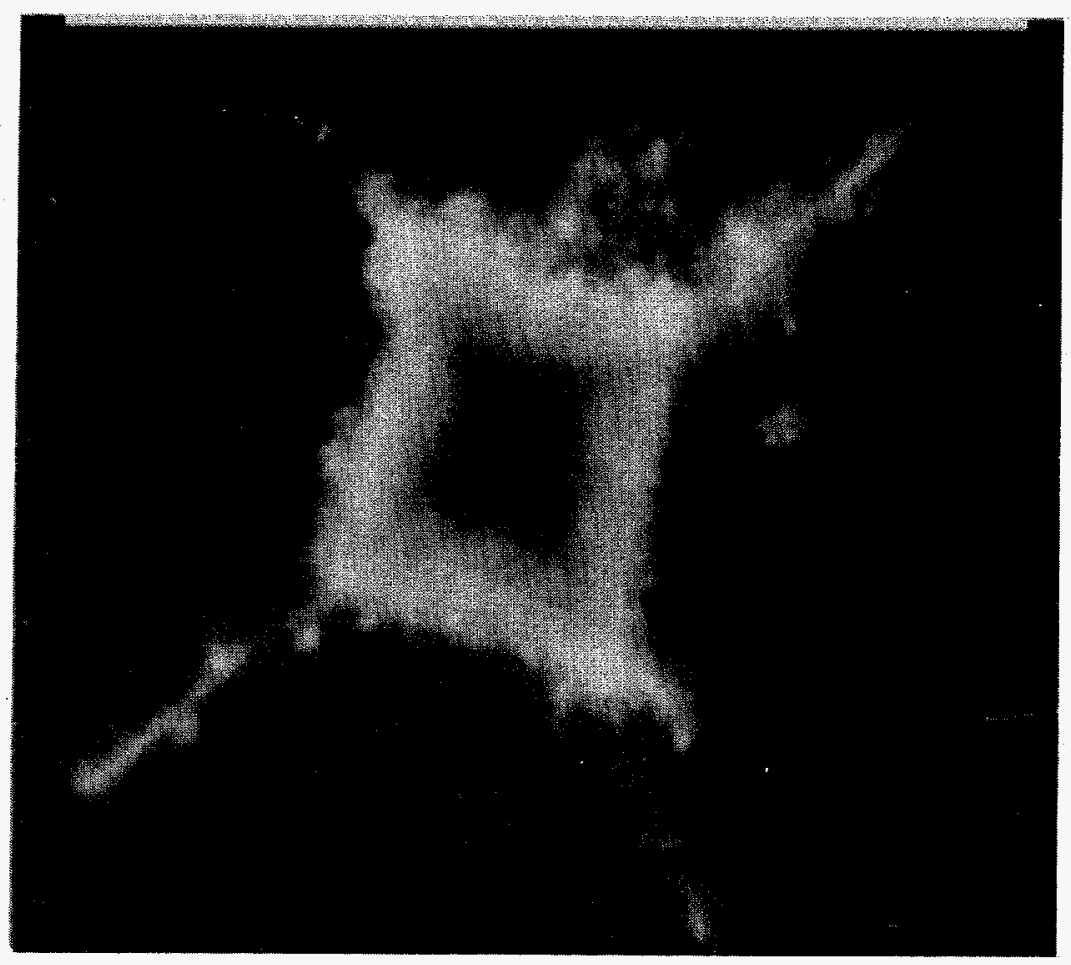

(b)

Fig. 5. Typical image results obtained: (a) visible light and (b) UV after treatment with fluorescent penetrant. Corner to corner across the indent is $\sim 100 \mu \mathrm{m}$. 
Table 3. Surface Roughness for Penetrant Studies

\begin{tabular}{|c|c|c|}
\hline Sample Number & Ra, $\mu \mathrm{m}$ & $\mathrm{Rq}, \mu \mathrm{m}$ \\
\hline $\mathrm{I}$ & .056 & .070 \\
\hline $\mathrm{II}$ & .054 & .071 \\
\hline $\mathrm{III}$ & .089 & .109 \\
\hline $\mathrm{IV}$ & .099 & .126 \\
\hline $\mathrm{V}$ & .069 & .109 \\
\hline $\mathrm{VI}$ & .186 & .281 \\
\hline $\mathrm{VII}$ & .161 & .201 \\
\hline $\mathrm{VIII}$ & .170 & .214 \\
\hline $\mathrm{IX}$ & .122 & .153 \\
\hline $\mathrm{X}$ & .124 & .159 \\
\hline $\mathrm{XI}$ & .046 & .060 \\
\hline
\end{tabular}

\section{Penetrant Comparison}

With the limited number of samples, a comparison between the two penetrants was made by dividing the samples into two groups. Each sample was given three indents of $10 \mathrm{~kg}$. Since the crack length was determined by measuring from tip to tip across a diagonal, this yields two cracks per indent or six cracks per sample. The first group, samples $2,4,6,8,10$, were treated with $\mathrm{ZL}-37$ and the second group, samples 3 , $5,7,9,11$, were treated with $\mathrm{RC}-88$ penetrant. The tip to tip crack length as seen using the penetrant were then measured, using the microscope.

To remove the penetrant the samples were then cleaned in an ultrasonic bath of distilled water and detergent (ALCONOX) followed by an ultrasonic bath in plain water and drying at $\sim 160^{\circ} \mathrm{F}$. After this cleaning procedure none of the cracks were visible under UV light. 
However, some of the crushed areas around the indents were faintly visible.

The samples were then reinspected but with the other penetrant. That is samples $2,4,6,8,10$ were treated with $\mathrm{RC}-88$, and samples 3,5 , $7,9,11$, treated with ZL-37. The crack lengths were again measured. The results are given in Table 4. Several observations can be made: First, the crack lengths for the same sample measure the same within one standard deviation for the two penetrants; second, crack lengths for samples of the same materials matched closer than the crack lengths of different materials and third, crack lengths for silicon carbide averaged $372 \mu \mathrm{m}$ while for silicon nitride the average was $283 \mu \mathrm{m}$.

One possible reason for the wide scatter in crack lengths even for the same indent on the same sample is the subjective nature of picking the end points of a crack.

Figure 6 illustrates an observation we saw frequently. Surrounding each indent is a "cloud" of fluorescence. Under visible light this surface appears undisturbed. After exposure to the penetrant, the image shows areas of fluorescence, that are not removed by the detergent action of the remover. The fluorescence must remain under the surface where the remover is not effective. The stress of the indent must open a network of micro-micro cracks through the material that allows penetration of the penetrant. The surface away from the indent is undisturbed.

This same phenomenon shows up on other areas than around indents. It appears randomly over the surface, many times around a pit or inclusion. Figure 7 shows the effect around a pit. Perhaps this is an indication of surface damage caused by heavy grinding, the damage being accentuated by the discontinuity. This phenomenon deserves further study.

Importance of Optical Magnification

After a limited study, we have concluded that 100X magnification provides excellent detectability. However, 50X may be sufficient for many applications. This is significant as the speed of inspection would be greatly reduced if $100 \mathrm{X}$ is needed. 
Table 4. Optically Measured Crack Lengths Using Fluorescent Penetrant Indenter Load: $10 \mathrm{Kg}$ Optical Magnification: 100X

\begin{tabular}{|c|c|c|c|}
\hline Sample \# & $\begin{array}{c}\text { Crack Length } \\
\mu \mathrm{m}\end{array}$ & Penetrant & Material Type \\
\hline \multicolumn{4}{|l|}{ Step 1} \\
\hline II & $407 \pm 24$ & ZL-37 & NT $230 \mathrm{SiC}$ \\
\hline IV & $372 \pm 26$ & ZL-37 & Hexaloy S.A. SiC \\
\hline $\mathrm{VI}$ & $275 \pm 14$ & ZL-37 & $\mathrm{SN} 253 \mathrm{Si}_{3} \mathrm{~N}_{4}$ \\
\hline VIII & $291 \pm 24$ & ZL-37 & $\mathrm{GN} 10 \mathrm{Si}_{3} \mathrm{~N}_{4}$ \\
\hline $\mathrm{X}$ & $262 \pm 16$ & ZL-37 & NT $164 \mathrm{Si}_{3} \mathrm{~N}_{4}$ \\
\hline III & $341 \pm 32$ & $\mathrm{RC}-88$ & Hexaloy SA SiC \\
\hline $\mathrm{V}$ & $303 \pm 48$ & $\mathrm{RC}-88$ & $\mathrm{SN} 253 \mathrm{Si}_{3} \mathrm{~N}_{4}$ \\
\hline VII & $277 \pm 9$ & $\mathrm{RC}-88$ & $\mathrm{GN} 10 \mathrm{Si}_{3} \mathrm{~N}_{4}$ \\
\hline IX & $269 \pm 10$ & $\mathrm{RC}-88$ & NT $164 \mathrm{Si}_{3} \mathrm{~N}_{4}$ \\
\hline \multicolumn{4}{|l|}{ Step 2} \\
\hline II & $379 \pm 36$ & $\mathrm{RC}-88$ & NT $230 \mathrm{SiC}$ \\
\hline IV & $384 \pm 10$ & $\mathrm{RC}-88$ & Hexaloy S.A. SiC \\
\hline VI & $282 \pm 14$ & $\mathrm{RC}-88$ & $\mathrm{SN} 253 \mathrm{Si}_{3} \mathrm{~N}_{4}$ \\
\hline VIII & $278 \pm 14$ & $\mathrm{RC}-88$ & GN $10 \mathrm{Si}_{3} \mathrm{~N}_{4}$ \\
\hline $\mathrm{x}$ & $264 \pm 20$ & $\mathrm{RC}-88$ & $\mathrm{NT} 164 \mathrm{Si}_{3} \mathrm{~N}_{4}$ \\
\hline III & $346 \pm 36$ & ZL-37 & Hexaloy S.A. SiC \\
\hline V & $325 \pm 18$ & ZL-37 & $\mathrm{SN} 253 \mathrm{Si}_{3} \mathrm{~N}_{4}$ \\
\hline VII & $288 \pm 27$ & ZL-37 & GN $10 \mathrm{Si}_{3} \mathrm{~N}_{4}$ \\
\hline IX & $283 \pm 10$ & ZL-37 & NT $164 \mathrm{Si}_{3} \mathrm{~N}_{4}$ \\
\hline
\end{tabular}




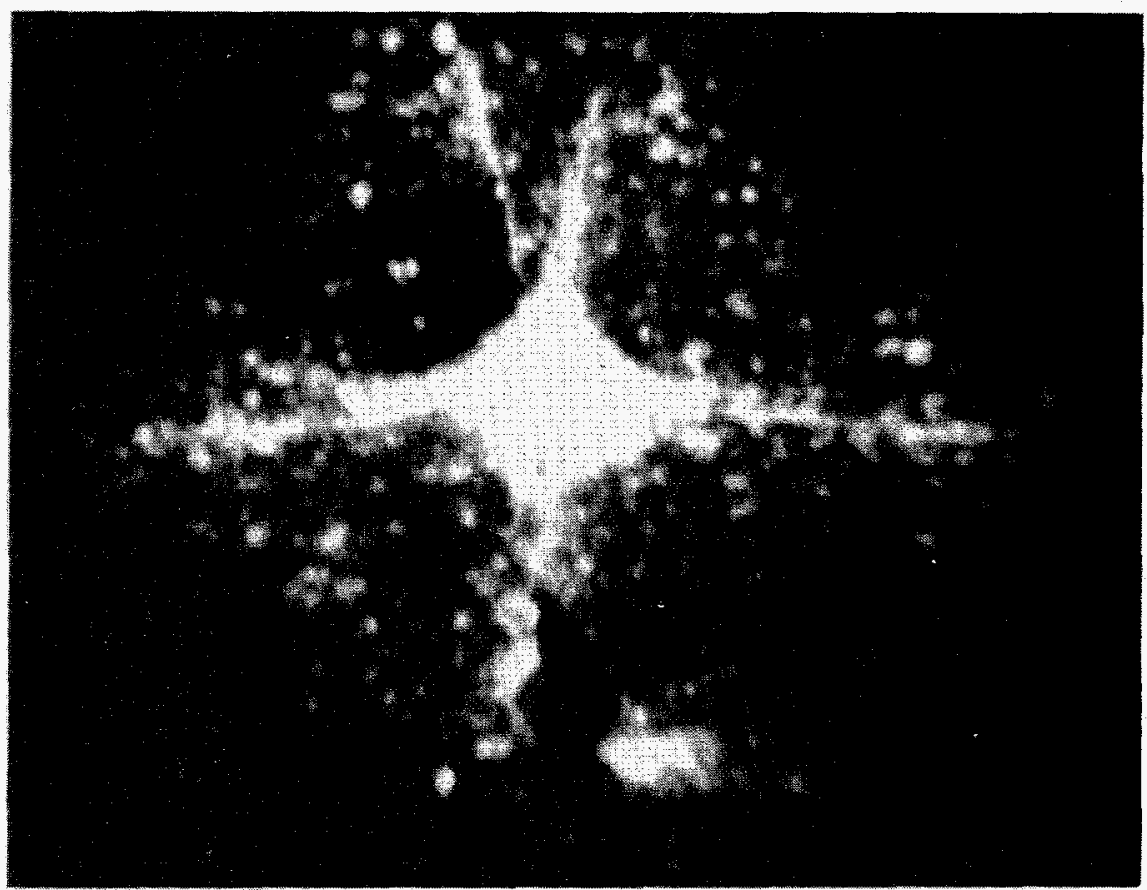

Fig. 6. An indent in Sample I surrounded by a cloud of fluorescence $(100 \mathrm{X})$.

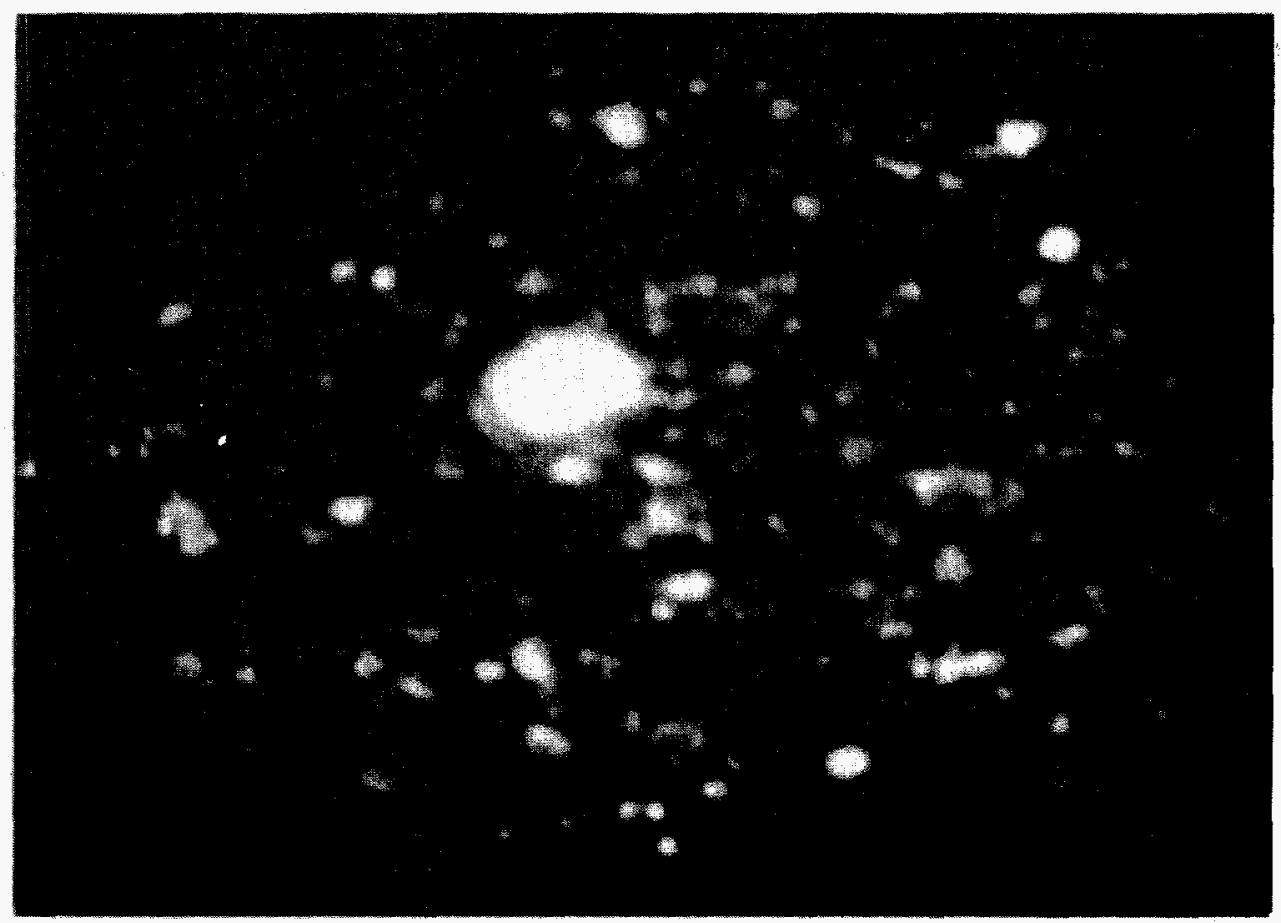

Fig. 7. Disturbed material on Sample I surrounding a void (400X). The void is $\sim 7 \mu \mathrm{m}$ dia. 


\section{Recommendations}

Based on the results of this limited study, we recommend the following:

1. Use only fluorescent penetrants for detection of surfacebreaking cracks generated by machining.

2. The protocol to be followed should utilize high $(>25 X)$ optical magnification with UV light delivered to the test piece.

3. Verification of crack detection sensitivity should be established through a limited 1-year follow-on study whereby the Vicker's indent is polished away and crack length measured using fluorescent penetrant.

4. Automation of detection should be assessed as part of a limited one-year follow-on using the digital image data acquisition and new advanced digital image processing methods.

\section{References}

1. Horton, S. A. "Detection of Surface Defects in Ceramic Rolling Elements," in Fourth International Symposium on Ceramic Materials and Components for Engines, June 1991, Göteborg, Sweden, pp. 897-904.

2. Kölker, H., Henze, P., Schwetz, K. A. and Lipp, A., "X-ray Microfocus and Dye Penetrant Techniques for Crack Detection in Ceramics," in Third International Symposium on Ceramic Materials and Components for Engines, V. J. Tennery, et., Las Vegas, NV, USA, Nov. 1988, pp. 1122-1129.

3. Malins, R. J., McCall, D. and Rhodes, G. W., "Systems Level Considerations for Environmentally Responsive Fluorescent Penetrant Testing," Mat. Eval. Vol. 51, No. 3, 338-352, Mar. 1993. 
4. Beriozkina, N. G., Larichev, M. N., Leipunsky, I. O., Eremin, G. L., and Dergunov, N. M., "Indicator Capillary-Diffusion Method for Nondestructive Defectoscopy of Composite Materials," in Moscow International Composites Conference (MICC), Nov. 1416, 1990, Moscow, Elsevier Science, UK (1991), pp. 773-776. 

Appendix A: Product Sheets

A.1 ZL-37/ZR-10B
A.2 RC-88/ER-83A 


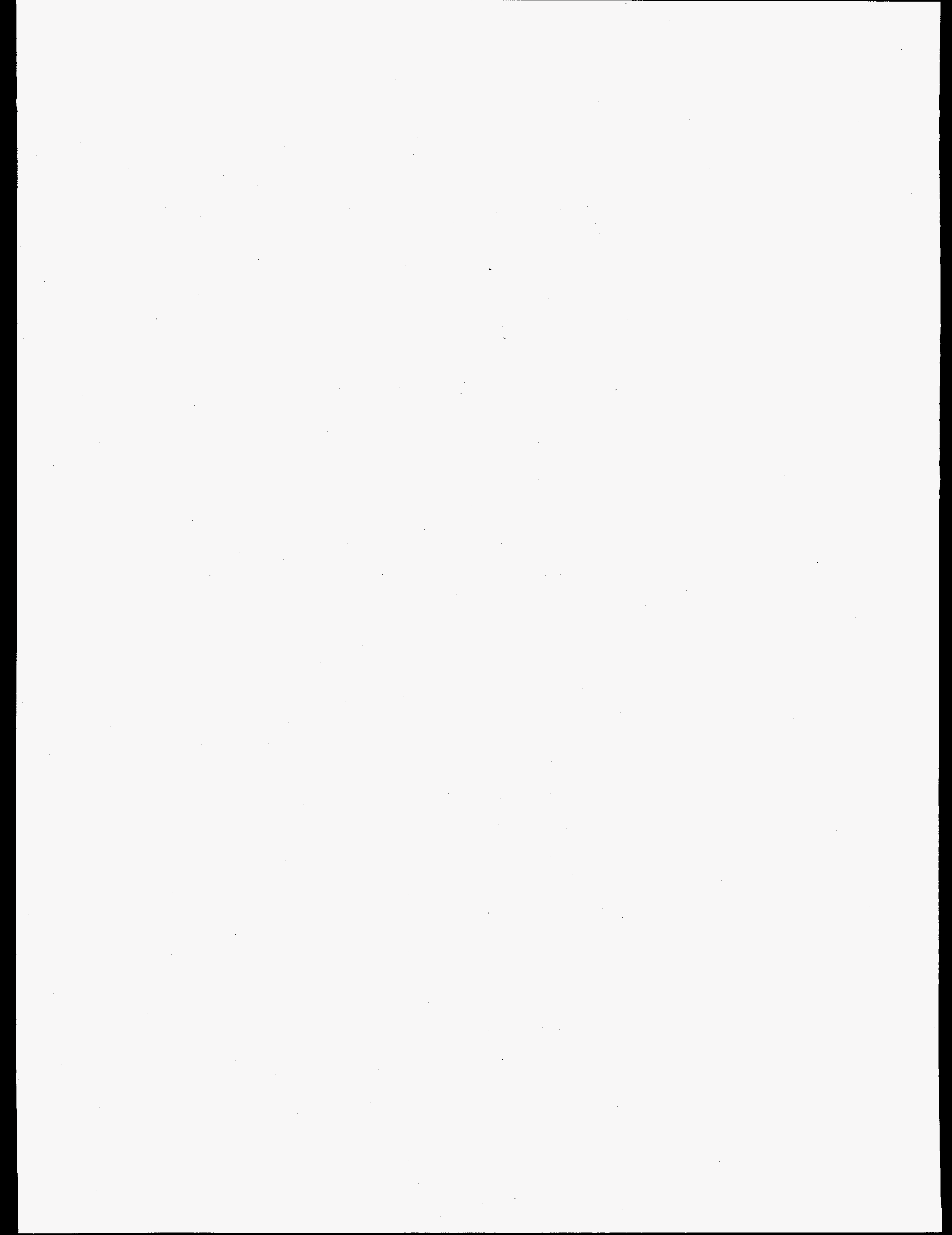




\section{ZYGLO Post Emulsifiable Penetrant (ZL-37)}

Effective: February 18, 1992

Supercedes: January 21, 1992

\section{General Description}

ZL-37 is a post emulsifiable fluorescent penetrant, used reliably for a wide range of ultrahigh sensitivity, critical applications.

ZL-37 is ideally suited for titanium turbine components, investment castings, and other high stress critical components where detection of fine, tight and broad open shallow discontinuities is a must.

ZL-37 is formulated to be impervious to water to assure against being overwashed from defects. ZL-37 requires the application of a lipophilic emulsifier or a hydrophilic emulsi fier to render it washable with water, and the resultant mixture is biodegradable.

ZL-37 is formulated for rapid separation from water, for efficient effluent clean-up by coalescer, separation settling pond or charcoal filtration.

ZL-37 fluoresces a bright greenish-yellow color under ultraviolet radiation. Use blacklight sources with peak wavelength of 365 nanometers such as MAGNAFLUX ${ }^{(2)}$ Z100. $\mathrm{ZL}-37$ is formulated to produce heat stable fluorescent indications under normal drying conditions $\left(140^{\circ} \mathrm{F} / 60^{\circ} \mathrm{C}\right)$.

ZL-37 meets OSHA requirements for Class III B liquids due to its high $f$ lash point and can be used in open dip tanks.

\section{Composition}

ZL-37 is composed of alkyl aryl phosphate, high boiling petroleum oils, and fluorescent dyes.

\section{Safety}

$Z L-37$ is intended for industrial use by qualified personnel only.

Do not smoke or eat while using ZL-37. Wash hands thoroughly after use. To protect hands from staining and drying out, protective hand wear is recommended.

Store $\mathrm{ZL}-37$ in closed containers away from open $f$ lame or heat.

Department of Labor Material Safety data sheets available. 


\section{ZYGLO Post Emulsifiable Penetrant}

(ZL-37)

Product Data Sheet

ZY-PE-11a

Typical Properties (Not a Specification)

Viscosity @ $1000 \mathrm{~F}$

Flash Point

Density

Sulfur

Chlorine

Sodium

Fluorine
$13.4 \mathrm{cs}$

Greater than $200^{\circ} \mathrm{F}$ (P.M.C.C.) $\left(93.3^{\circ} \mathrm{C}\right.$ )

$8.1 \mathrm{lbs} . / \mathrm{gal}$. (959 gms./L)

Less than $1000 \mathrm{ppm}$

Less than $1000 \mathrm{ppm}$

Less than $100 \mathrm{ppm}$

Less than $50 \mathrm{ppm}$

Noncorrosive per MIL-I-25135

Compatible with titanium and high nickel alloys

Like all MAGNAFLUX materials, ZL-37 is closely controlled to provide unique batch to batch consistency and uniformity to assure optimum process control and inspection reliability. Batch cer tification available upon request.

\section{Method of Application}

Test parts must be clean, free of all oil, grease or other foreign contaminating substances, and dry, before penetrant is applied. ZL-37 can be applied by immersion dip, brush or flow on, conventional or electrostatic spray. Area to be inspected must be completely covered with penetrant.

\section{Penetration Time and Temperature}

The generally accepted minimum penetration time is 2 to 5 minutes. Some specifications may require longer dwell times. $\mathrm{ZL}-37$ is generally used between $500 \mathrm{~F}$ to $1250 \mathrm{~F}$

\section{Penetrant Removal}

ZL-37 requires the use of a Zyglo lipophilic emulsifier or hydrophilic emulsifier to render it water washable.

When using ZL-37 with hydrophilic emulsifier it is advantageous to prerinse the ZL-37 covered part with plain water spray $(500 \mathrm{~F}-1000 \mathrm{~F})(20-40 \mathrm{psig})$ before the emulsifier application. The prerinse removes the bulk of the surface penetrant but leaves a thin film, sufficient for quality inspection. The purpose of the prerinse is to lower the amount of penetrant entering the emulsifier tank (dip application), contaminating it and lowering its activity. The prerinse effluent can be treated to separate the penetrant and water to the extent that the water can be reused in the prerinsing operation.

Recommended emulsifiers for use with $\mathrm{ZL}-37$ are:

$$
\text { ZE-3 ZE-4B ZR-10B }
$$




\section{Penetrant Removal (Continued)}

For inspection of small areas the solvent wipe technique is commonly employed, using SKC-NF or SKC-S Cleaner/Remover. Moisten a clean wiping media with SKC-NF or SKC-S and wipe inspection area free of surface penetrant. Do not flood surface with cleaner/remover as sensitivity may be impaired.

\section{Developer Application}

Zyglo developers should be used to maximize the sensitivity of ZL-37. Aqueous developers are applied prior to drying; dry powder and nonaqueous developers after drying $(1400 \mathrm{~F} / 600 \mathrm{C})$.

Recommended developers for use with ZL-37 are:

$\begin{array}{lll}Z P-4 B & Z P-9 F & \text { SKD-NF } \\ \text { ZP-5B } & \text { ZP-13A } & \text { SKD-S } \\ \text { ZP-9E } & \text { ZP-14 } & \text { SKD-S2 }\end{array}$

MIL-I-251 35 Classification

"E" Revision - Type I, Method B, Level 4 Penetrant with ZE-3 or ZE-4B emulsifier. "E" Revision - Type I, Method D, Level 4 Penetrant with ZR-1OB emulsifier (20\%).

Specification Compliance

MIL-I-25135

MIL-I-6866

MIL-STD-271

Boeing BAC 5423 PSD $6-46$ or $8-4$

Garrett EMS 52309E

Pratt \& Whitney

PMC 4354-2

\author{
ASTM E-165 \\ ASME B \& PV Code, Sec. V \\ A.MS-3157 \\ MCDonnell Douglas PS-21202 \\ AECL \\ MIL-STD-2132
}

How Supplied
1 gallon can
5 gallon pail
20 gallon drum
55 gallon drüm

\section{Coverage}

1 gallon approximately 900 square feet

Warning:

Penetrants attack and even dissolve many kinds of plastic pipe. Polyvinyl chloride (PVC) pipe is especially vulnerable, and can crumble after only a few days of exposure. Even diluted penetrant rinsings attack it rapidly. ABS plastic pipe is nearly as sensitive. When installing plumbing to handle penetrant rinsings, use metal pipe. 


\section{MAGNAFLUX MATERIAL SAFETY DATA SHEET}

ZYGLO' PENETRANT ZL-37

1. IDENTIFICATION

Company:

Address:

Telephone No.:

Produce Use:

Packagos:

NFPA Rating:

PIN:

Revision Date:
MAGNAFLUX

7301 West Ainslie Avenue, Harwood Hts., Illinois 60656

(708) 867-8000 (Off-Hour Emergency Number - CHEMTREC - 1-800-424-9300).

Fluorescent inspection penetrant

1 gallon cans, 5 gallon pails, 20 gallon and 55 gallon drums

Heaith 1. Flammability 1, Reactivity 0

None

June 4, 1993

2. HAZARDOUS INGREDIENTS

\begin{tabular}{|c|c|c|c|c|}
\hline ingredient & Wh.Mr. $\%$ & CASE & $\underline{T L V}$ & $\underline{p} \underline{\underline{E}}$ \\
\hline $\begin{array}{l}\text { Severoly mydrotreated heavy nephthonic distlllates } \\
\text { (petrolecumf }\end{array}$ & $30-60$ & 64742.52 .5 & not avail. & not avail. \\
\hline Isodecyl diphenyl phosphate & $15-40$ & 29761.21 .5 & not aval. & not avail. \\
\hline $\begin{array}{l}\text { Polyloxy-1.2-othenedivll,e - (nonyiphenyl)-whydroxy } \\
\text { MAZARDS IDENTIFICATION }\end{array}$ & 3.7 & $9016.45-9$ & not aval. & not avail. \\
\hline
\end{tabular}

\section{POTENTIAL HEALTH EFFECTS}

Skin Contact: Can irritate by removing natural skin oils on long of repeated exposures.

Eyes: $\quad$ May cause irritation.

Inhalation: Not significant at room temperatures. When heated or sprayed. ZL-37 vapors may cause dizziness and nausea.

Ingestion: Not significant in small (mouthful) amounts.

Medical conditions known to be aggravated by exposure to product: None

$\therefore \quad$ FIRST AID

Skin Contact: Wash off with soap and water. Use soothing lotion.

Eyes: $\quad$ Rinse carefully under upper and lower eyelids using plenty of water.

Inhalation: $\quad$ Remove to fresh air if dizzy or nauseated.

ingestion: Do not induce vomiting. Accidental ingestion of a small mouthiul is not expected to cause significant harm.

NOTE: In all severe cases, contact physician immediately. Local telephone operators can furnish number of regional poison control center.

इ. FIRE HAZARD

Conditions of flammability:

Flash point:

Flammable limits in air:

Extinguishing media:

Special fire fighting procedures:

Hazardous combustion products:

Unusual fire hazards:
Heating above $200^{\circ} \mathrm{F}\left(93^{\circ} \mathrm{C}\right)$ in presence of ignition sources.

Min. $200^{\circ} \mathrm{F}\left(93^{\circ} \mathrm{C}\right)$ (Pensky-Martens closed cup)

$1 \%$ to $6 \%$

Carbon dioxide. foam

Keep containers cool with water spray. Do not spray water directly on burning ZL-37. It may float and spread the fire.

Smoke, soot, oxides of carbon and nitrogen.

None

5. ACCIDENTAL RELEASE MEASURES

Mop up or sweep up with absorbent. (For disposal, see Section 13.)

7. HANDLING AND STORAGE

Avoid breathing spray mist.

Avoid eye contact.

Avoid repeated or prolonged skin contact.

Store away from heat source.

3. EXPOSURE CONTROLSIPERSONAL PROTECTION

Controls:

Personal protection:
None, uniess applied as spray. Use where ventilation will carry spray mist away from occupied areas: Wear safety glasses to protect eyes. Wear nitrile rubber gloves if hand exposure is unavoidable. Respirator with filter if sprayed in enclosed, unventilated space.

Page 1 of 2 (ZL-37)

A Division of lllinois Tool Works Inc

7301 West Ainslie Avenue Harwocd Heights. IL 60656 Telephone: 708 867-8000 
9. PHYSICAL PROPERTIES

Initial boiling point (bulk):

Percent volatile:

Density/sp. gravity:

Water solubility:

pH:

10. STABILITY ANO REACTIVITY

Stability:

incompatibility:

Hazardous decomposition products:

Reactivity:

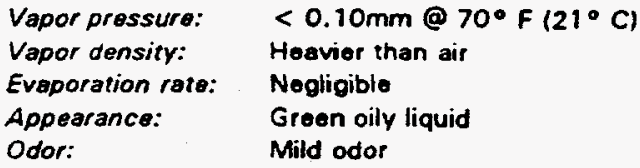

Vapor pressure:

Vapor density:

Eveporation rate:

Appearance:

Odor:

$<0.10 \mathrm{~mm} @ 70^{\circ} \mathrm{F}\left(21^{\circ} \mathrm{C}\right)$

Heavier than air

Negligible

Green oily liquid

Mild odor

i1. TOXICOLOGICAL INFORMATION

Carcinogenicity:

Threshold limit value:

WHMIS information (Canada):

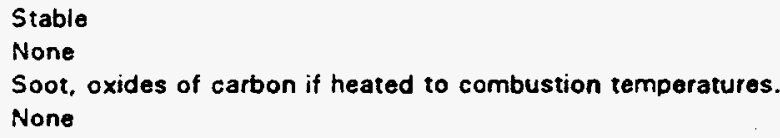

Contains no known or suspected carcinogens listed with OSHA, IARC, NTP, or ACGIH. $5 \mathrm{mg} / \mathrm{m}^{3}$ for oily mist

According to available information, the ingredients have not been found to show reproductive toxicity, teratogenicity, mutagenicity, skin sensitization, or synergistic toxic effects with other materials.

12. ECOLOGICAL INFORMATION

No data is available on ZL-37. It floats on water and can be skimmed off. Its low vapor pressure may exempt it from VoC restrictions.

i3. DISPOSAL

As a non-hazardous oily waste, incinerate or send to waste handler who can blend it into secondary fuels.

RCRA:

U.S. EPA Waste Number:

Not a hazardous waste

None

i4. TRANSPORTATION

U.S. DOT: 49 CFR 172.101 Hazardous Materials Table

Proper shipping name:

Bulk

Hazard class or division:

None. not restricted

Identification No.:

Packing Group:

None

None

None

i5. REGULATORY INFORMATION

TSCA:

CERCLA:

All ingredients are listed in TSCA inventory.

Not reportable

No reportable ingredients

SARA TITLE III, Section 313:

California Proposition 65:

WHMIS Class (Canada):

Contains nothing on this list

D.2B

Note: This MSDS has been prepared to meet WHMIS (Canada) requirements with the exception of using 16 headings.

16. OTHER INFORMATION

Revision Statement:

Supersedes:

The MSDS format has been alygred to conform to WHMIS

(Canada) requirements in Sections $1,2,5,9,11,13,15,16$

Signed by: MSDS dated $1 / 20 / 93$

Bruce C. Graham, Chief Chemist

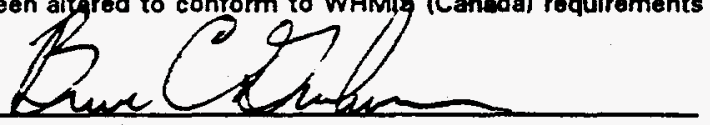

Page 2 of $2(Z L-37)$ 


\section{ZYGLO Hydrophilic Emulsifier} (ZR-10B)

Product Data Sheet

ZY-E-6

Effective: April 15, 1988

Supercedes: November 15, 1985

\section{General Description}

ZR-10B is a biodegradable, pinkish, slightly viscous liquid. $Z R-10 B$ is a $100 \%$ active concentrate which is diluted in water when used as an emulsifier for Zyglo PE penetrants. $\mathrm{ZR}-10 \mathrm{~B}$ is very low in sulfur, hologens and sodium content.

Utilization of ZR-10B Hydrophilic Emulsifier affords such advantages as: minimization of fluorescent background on rough surfaces, minimization of bleedout from hollow parts, reduced consumption of expendable materials, ease of use in close loop systems and reduced effluent pollutants. ZR-10B Hydrophilic Emulsifier yields the most reliable and reproducible test results due to its controlled Zyglo PE penetrant removal.

Composition

$\mathrm{ZR}-10 \mathrm{~B}$ is composed of polyols and surface active agents.

Safety

$\mathrm{ZR}-10 \mathrm{~B}$ is intended for industrial use by qualified personnel only.

Do not smoke or eat while using NDT materials. Wash hands thoroughly after use. Protective hand wear is recommended to prevent drying of skin. If $\mathrm{ZR}-10 \mathrm{~B}$ solution is sprayed, avoid breathing mist, either by using adequate ventilation or by wearing respirator with mist filter.

Department of Labor Material Safety data sheets available upon written request.

Typical Properties (Not a Specification)

Color

Viscosity @ $100^{\circ} \mathrm{F}$

Flash Point

Density a $60^{\circ} \mathrm{F}$

Water Tolerance

Corrosion

Sulfur

Chlorine

Sodium

Fluorine
Pinkish Red

42.3 Centistokes

Greater than $200^{\circ} \mathrm{F}\left(93^{\circ} \mathrm{C}\right)$ P.M.C.C.

$8.35 \mathrm{lbs} . / \mathrm{gallon}(1003 \mathrm{gms} / \mathrm{L})$

Infinite

Non-corrosive per MIL-I-25135

Less than $1000 \mathrm{ppm}$

Less than $1000 \mathrm{ppm}$

Less than $100 \mathrm{ppm}$

Less than $50 \mathrm{ppm}$

Like all Magnaflux Corporation materials $\mathrm{ZR}-10 \mathrm{~B}$ is closely controlled to provide unique batch to batch consistency and uniformity to assure optimum process control and inspection reliability. Batch certification available upon request. 
ZYGLO Hydrophilic Emulsifier

(ZR-10B)

Product Data Sheet

ZY-E-6a

\section{$\underline{\text { Pre-Rinse }}$}

The pre-rinse step is recommended before the application of a hydrophilic emulsifier like $\mathrm{ZR}-10 \mathrm{~B}$. Pre-rinse is a water spray employed to mechanically reduce the film of $\mathrm{PE}$ penetrant on a part before entering the emulsifier bath. This process step prolongs the emulsifier bath life by lowering the amount of penetrant contaminating the bath. The pre-rinse and hydrophilic emulsifier process are ideally suited for closed loop low pollution systems.

\section{Application and Emulsification}

$\mathrm{ZR}-10 \mathrm{~B}$ concentrate is diluted in water before it is used as an emulsifier/remover. The hydrophilic emulsifier is generally employed as a spray or an immersion dip. The concentration used will determine the amount of contact time required to remove the surface penetrant.

\section{Spray Method}

If the spray method of emulsifier application is used, an injector or metering pump is used to control the concentration. The general spray concentration range is $0.1 \%$ to $0.5 \%$ remover. Higher concentrations up to $5 \%$ may be used but care is required to avoid over removal. Spray removal should be employed under blacklight illumination to control removal of penetrant from the surface. A clean water rinse is recommended to eliminate e mulsifier/penetrant residues.

\section{Immersion Method}

If the immersion dip method is employed the general concentration range is $5 \%$ to $33 \%$ remover to water. The recommended concentration range is $20 \%$ to $33 \%$ which optimizes remover activity, bath life, economics and process rate. The penetrated part is immersed in the bath, which is gently agitated by mechanical or air means. The length of time the part is in the bath will vary with the concentration of the bath, the type penetrant being used, specification requirements and the desired results. At $20 \%$ concentration the immersion contact time generally ranges between $30-180$ seconds.

The immersion dip is followed by a clean water spray to remove any penetrant/emulsifier residues.

The use of foam, created by heavy agitation of the emulsifier bath, as a remover method is possible. The foam will act as a remover, however it is not as effective overall for maximum performance. The foam does not enter hollow parts as readily as the liquid immersion and will therefore be less effective. 


\section{ZYGLO Hydrophilic Emulsifier \\ (ZR-10B)}

Concentration Control

The concentration of hydrophilic remover baths can be monitored using a refractometer and the charts provided (Figures 1 and 2). The water content of the bath can also be determined using the procedure described in ASTM D-95.

\section{Specification Compliance}

MIL-I-25135

MIL-STD-6866

MIL-STD-271

Bechtel Matl. Proc. Guide SS-10

ASME B \& PV code, Sec. V

ASTM E-165

Stone \& Webster QAD 9.24
McDonnell Douglas P $\quad 21202$

Garrett EMS 52309

Boeing BAC 5423 PSD $6-46$ or $8-4$

FPL SQAD 1005

RDT F3-6T

AECL

Pratt \& Whitney PMC 4355-2

How Supplied

1 gallon can

5 gallon pail

20 gallon drum

55 gallon drum

References: Zyglo Process Data Sheets ZY-4, ZY-5

For price information, refer to Price Page. 
WMe

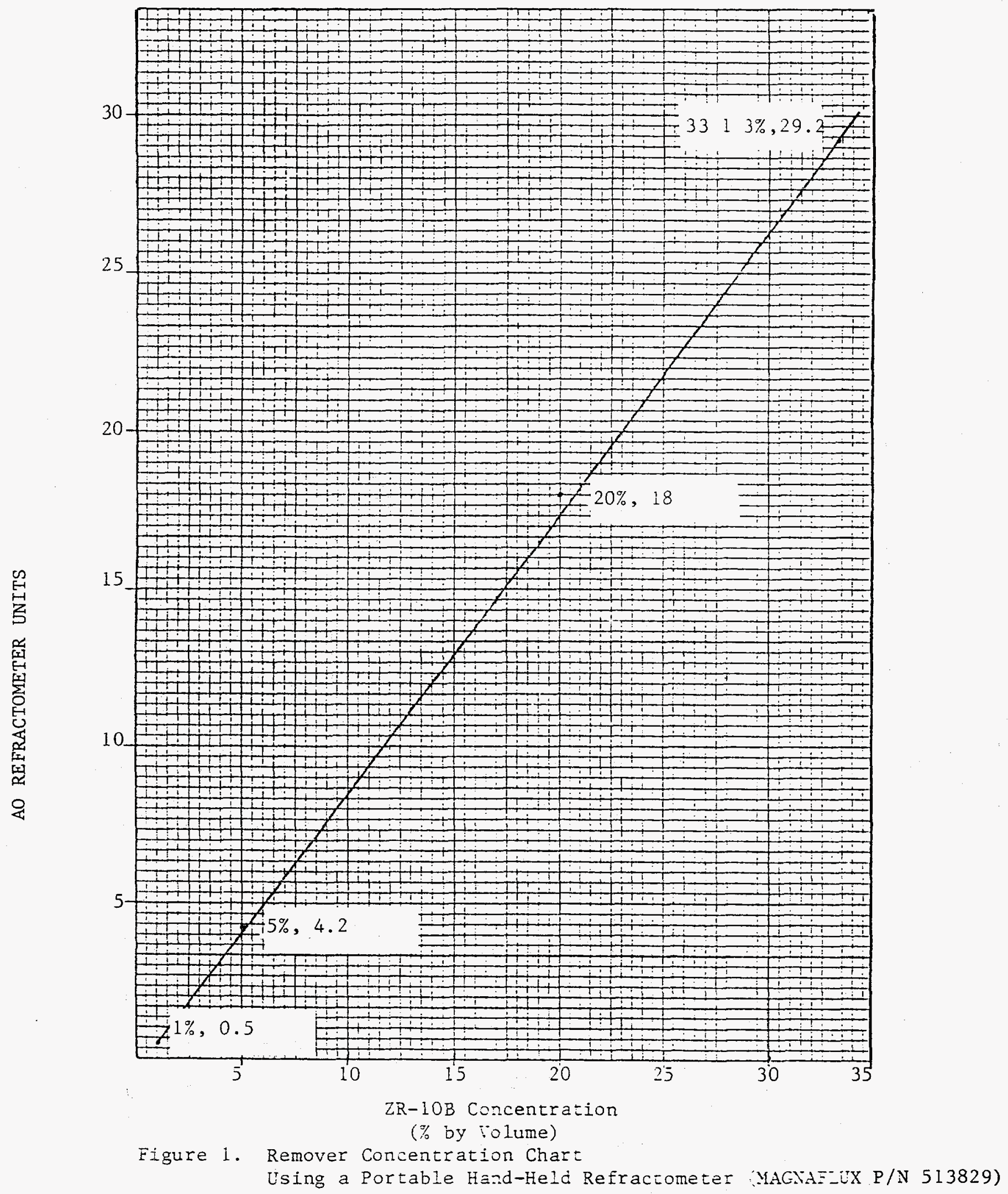

A Division of ilinois Tco Works Inc

7301 West Ainsiie Averie Harwood Heights. IL 60656 Teiephone: 708 867-8000 Fax: 708 867-6833 


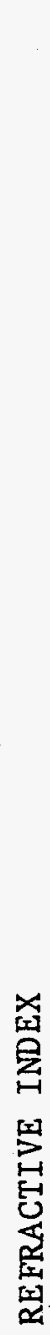

1.380

1.370

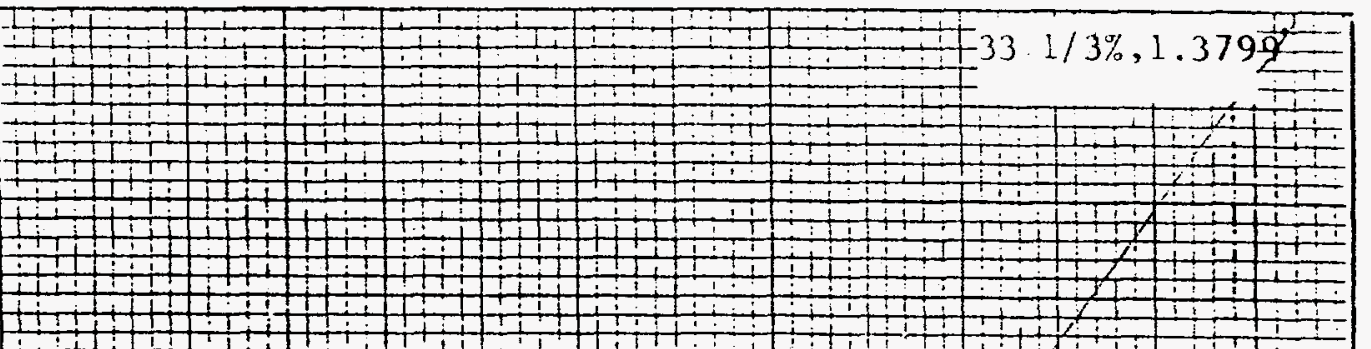

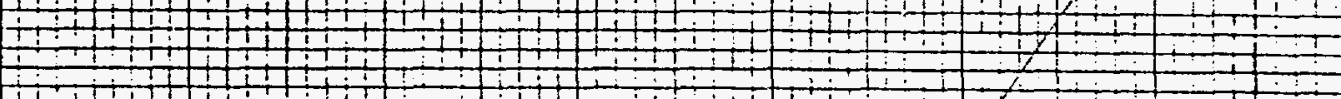

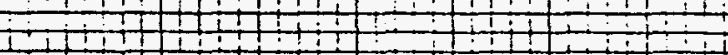

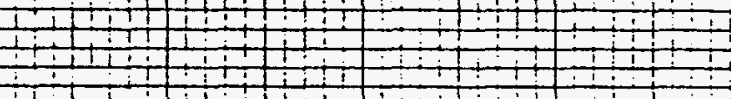

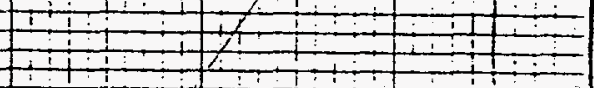
1 $11+1+1+1+1$

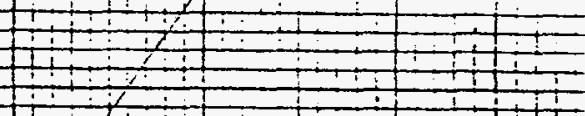
$1+1+1+1+1$ $1+1+1+1+1+1$

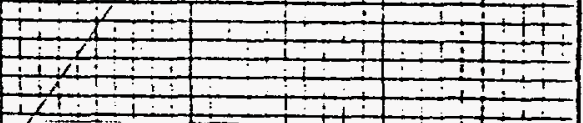
$4+14020 \% 1.3605$

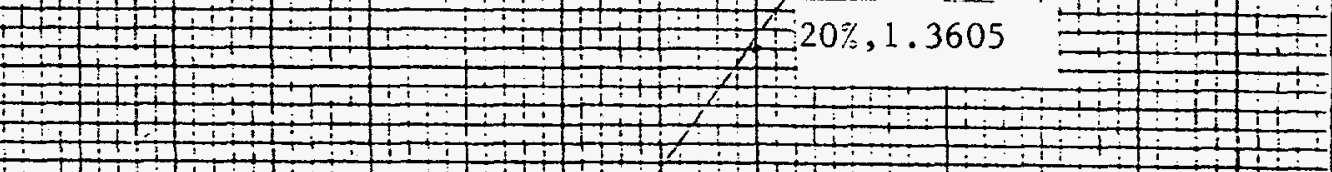

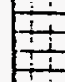

\subsection{0}<smiles>[C]#[C]</smiles>
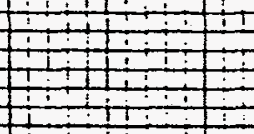
\begin{tabular}{c}
$1+1$ \\
\hline $1+11$ \\
\hline 101 \\
\hline
\end{tabular}

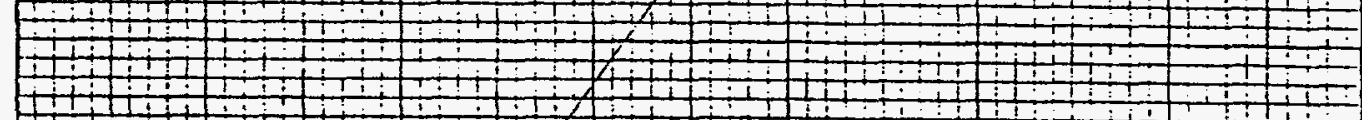

$+1$
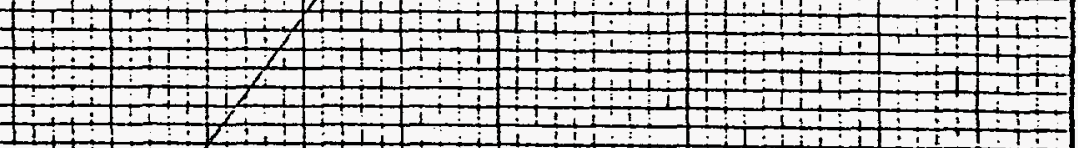

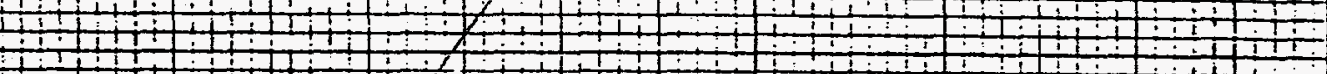

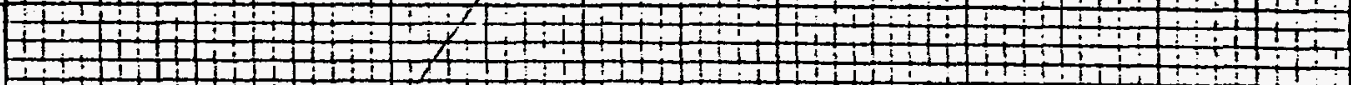

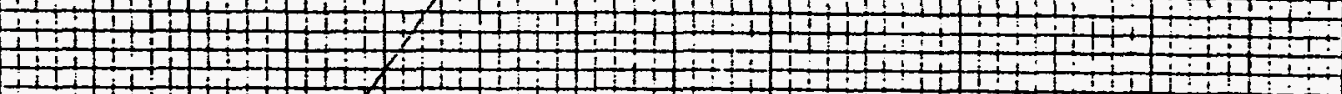

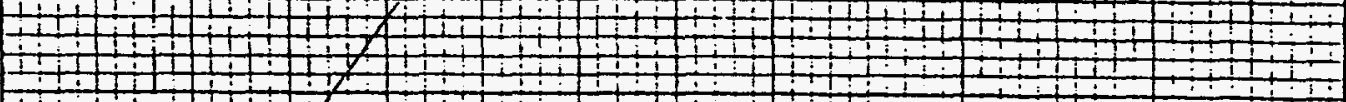

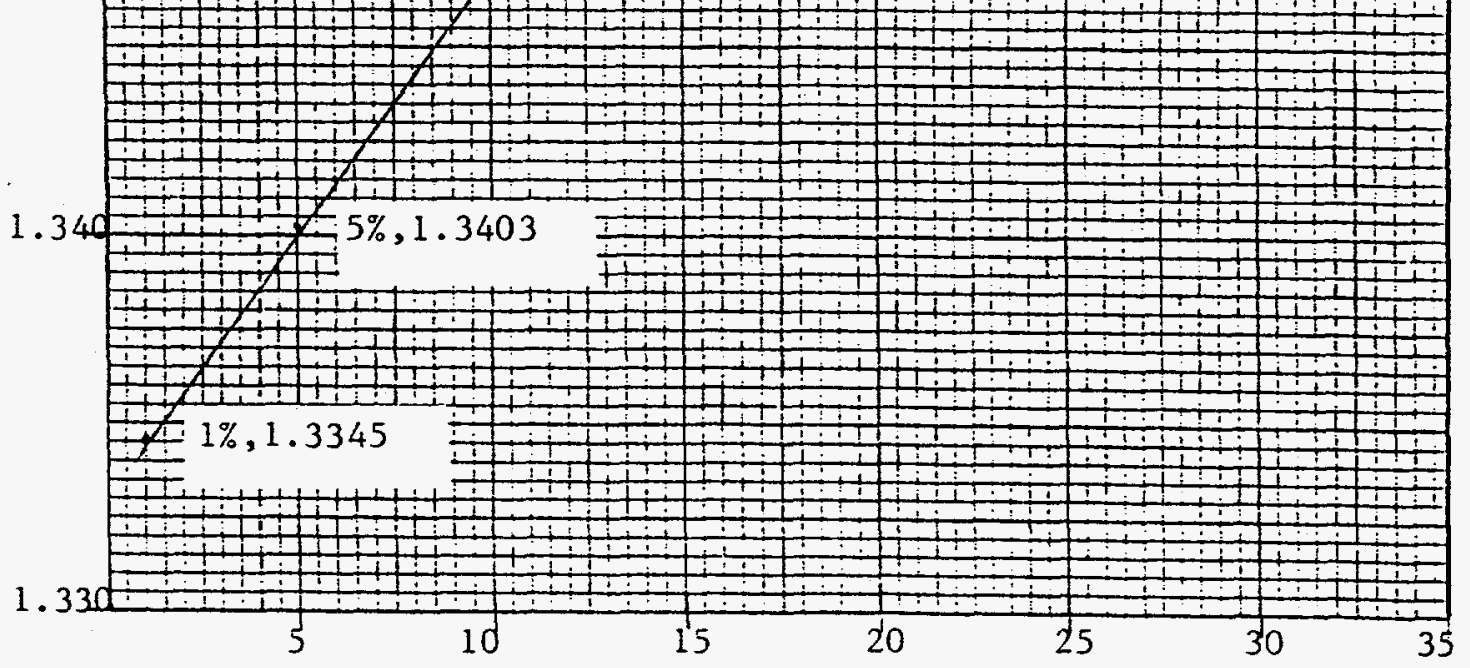

ZR-1OB CONCENTRATION

(\% by Volume)

Figure 2. Remover Concentration Chart

Using a Laboratory Precision Reiractometer 
MAGNAFLUX MATERIAL SAFETY DATA SHEET

ZYGLO' EMULSIFIER ZR-10B

1. IDENTIFICATION

Company:

Address:

MAGNAFLUX

Telephone No.: (708) 867-8000 (Off-Hour Emergency Number - CHEMTREC - 1-800-424-9300).

Product Use: $\quad$ Penetrant remover

Packages: $\quad 1$ gallon can, 5 gallon pail, 20 gallon and 55 gallon drums

NFPA Rating: Health 1, Flammability 1, Reactivity 0

PIN:

None

Revision Date: November 24, 1993

2. HAZARDOUS WGREDIENTS

inorodition

Polv loxy-1,2-othenediyl). olnonylphenyil)-w-hydroxy

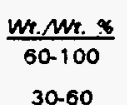
$\frac{\operatorname{cAs} E}{9016-45}$
$9016-45-9$
$107-41-5$

2-mothyr-2,4-pentencediol

$30-60$

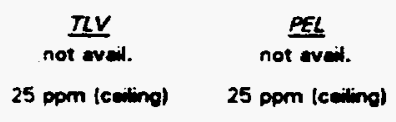

Lop
2 gho (orel/ret)
2.8 g/kg
(ordlouinee piol
$\underline{L C}$ not aved. not eveii.

3. HAZARDS IDENTIFCATION

\section{EMERGENCY OVERVIEW}

Bland, oily liquid which may irritate the skin and eyes.

Difficult to ignite, but will burn vigorously it engulfed in fire.

POTENTIAL HEALTH EFFECTS

Skin Contact: $\quad$ Can irritate by removing natural skin oils on long or repeated exposures.

Eyes: Irritating.

Inhalation: Not significant at room temperatures. When heated or sprayed, $2 R-10 B$ vapors may cause dizziness and nausea.

Ingestion: Not significant in small (mouthful) amounts.

Medical conditions known to be aggravated by exposure to product: None

$\therefore \quad$ FIRST AID

Skin Contact: Wash off with soap and water. Use soothing lotion.

Eves: $\quad$ Rinse carefully under upper \& lower eyelids using plenty of water.

Inhalation: Remove to fresh air.

Ingestion: Do not induce vomiting. Accidental ingestion of a small mouthful is not expected to cause significant harm.

NOTE: In all severe cases, contact physician immediately. Local telephone operators can furnish number of regional poison control center.

\section{FIRE HAZARD}

Conditions of flammability:

Flash point:

Flammable limits in air:

Extinguishing media:

Special fire fighting procedures:

Hazardous combustion products:

Unusual fire hazards:
Heating above $200^{\circ} \mathrm{F}\left(93^{\circ} \mathrm{C}\right)$ in presence of ignition sources.

Min. $200^{\circ} \mathrm{F}\left(93^{\circ} \mathrm{C}\right)$ (Pensky-Martens closed cup)

$1 \%$ to $6 \%$

Carbon dioxide, foam

Keep containers cool with water spray. In use, ZR-10B is dissolved into water, nearly eliminating its ability to burn.

Smoke, soot, oxides of carbon

None

ミ. ACCIDENTAL RELEASE MEASURES

Mop up or sweep up with absorbent. (For disposal, see Section 13.)

HANDLING AND STORAGE

Avoid breathing spray mist.

Avoid eye contact.

Avoid repeated or prolonged skin contact.

\section{EXPOSURE CONTROLSIPERSONAL PROTECTION}

Controls: $\quad$ None, unless applied as spray. Use where ventilation will carry spray mist away from occupied areas.

Personal protection: Wear safety glasses to protect eyes. Wear nitrile rubber gloves if hand exposure is unavoidable.

Respirator with filter if sprayed in enclosed, unventilated space.

A Division of illinois Tool Works Inc.

7301 West Ainslie Avenue Harwood Heights, IL 60656 Telephone: 708 867-8000 Fax: 708 867-6833 
PHYSICAL PROPERTIES

Initial boiling point (bulk):

Percent volatile:

Density/sp. gravity:

Water solubility:

oH:

\author{
Min. $385^{\circ} \mathrm{F}\left(196^{\circ} \mathrm{C}\right.$ ) (ASTM D-86) \\ None \\ 0.9 \\ $100 \%$ \\ Neutral
}

Vapor pressure: Vapor density: Evaporation rate: Appearence: Odor:
$<0.10 \mathrm{~mm} @ 70^{\circ} \mathrm{F} 121^{\circ} \mathrm{C}$ Heavier than air Negligible

Pink viscous liquid Mild odor

3. STABILITY AND REACTINITY
Stability:
Stable
incompatibility:
Stabie
Soot, oxides of carbon if heated to combustion temperatures.
Hazardous decomposition products:
Reactivity:
None

:0. TOXICOLOGICAL INFORMATION

Carcinogenicity:

Throshold limit value:

WHMIS information (Canada):

Contains no known or suspected carcinogens listed with OSHA, IARC, NTP, or ACGIH.

$5 \mathrm{mg} / \mathrm{m}^{3}$ for oily mist

According to available information, the ingredients heve not been found to show reproductive toxicity, teratogenicity, mutagenicity, skin sensitization, or synergistic toxic effects with other materials.

\section{$\because$ ECOLOGICAL INFORMATION}

No data is available on $\mathrm{ZR}-10 \mathrm{~B}$. It dissolves into water and is biodegradable. Its low vapor pressure may exempt it from voC restrictions.

2. DISPOSAL

As a non-hazardous oily waste, incinerate or send to waste handier who can blend it into secondary fuels.

RCRA:

Not a hazardous waste

U.S. EPA Waste Number:

None

$\therefore$ TRANSPORTATION

U.S. DOT: 49 CFR 172.101 Hazardous Materials Table

Proper shipping name:

Hazard class or division:

Bulk

Identification No.:

Nine, not restricted

Packing Group:

None

None

None

$\therefore$ REGULATORY INFORMATION

TSCA:

CERCLA:

All ingredients are listed in TSCA inventory.

Not reportable

No reportable ingredients

SARA TITLE III, Section 313

Contains nothing on this list

California Proposition 65

WHMIS Class (Canada):

D-2B

Note: This MSDS has been prepared to meet WHMIS (Canada) requirements with the exception of using 16 headings.

E. OTHER INFORMATION

Revision Statement:

Supersedes:

Section 2 - TLV and PEL values were corrected.

Signed by: MSDS dated 6/1/93

Bruce C. Graham, Chie Chemist

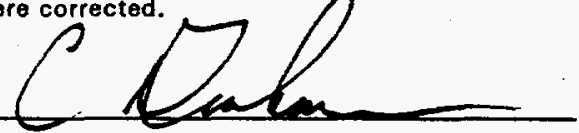

Page 1 of $2(Z R \cdot 10 B)$ 
Description: RC-88 is a nonwater-washable, ultra-high sensitivity (Level 4), fluorescent penetrant, formulated for super critical inspections. It is a grade above Shenwin RC-77 fluorescent penetrant. It is an OSHA Class IIIB material. Flash point over $200^{\circ} \mathrm{F}$. Complies with low-sulfur and lowhalogen requirements. Excellent heat and UV stability.

Special Features: RC-88 can be considered a special purpose material; formulated with a single objective:

\section{Io find the dangerous microscopic flaw. which other penetrant systems overlook!}

To do this, RC-88 is charged with a near maximum quantity of heat stable dyes. As a result, the visibility of dangerous microscopic crack indications is at a high level. Flaws, barely observable, or not visible at all, with other Level 4 penetrants are fully apparent with RC-88.

RC-88 was invented primarily for evaluating the critical components of turbine engines - discs, compressor blades, fan blades. It gives added assurance that flaws conducive to catastrophic failures will be detected, not overlooked.

Additionally, AC-88 provides a higher degree of heat and UV stability, which are especially important when detecting microscopic flaws, giving further assurance that extremely micorscopic flaw indications will not be lost in the drying oven, but will remain visible for detection.

Considering the cost of one overlooked catastrophic failure causing crack, RC-88 is not just cost effective, it is indispensable. In some areas, there is no excuse for not using the best matierial and process available.

While RC-88 is approved for use with both hydrophilic (Method D) and lipophilic (Method B) emulsifiers, only Method D (hydrophilic emulsifier) is recommended for highly critical inspections.

\section{Companion Materials:}

Developers -

Sherwin D-90G Dry Powder (form a)

Sherwin D-100 Nonaqueous (form d)

Sherwin D-100NF Nonaqueous (form d)

Sherwin D-110A.1 Nonaqueous (form c)

Sherwin D-113G. 1 Water Soluble (form b)

equivalent OPL-25135-listed developers

Emulsifiers - $\quad$ Sherwin ER-83A Hydrophilic Emulsifier (method D)

Sherwin ER-85 Lipophilic Emulsifier (method B)

Removers - $\quad$ Sherwin DR-61 (Class 1)

Sherwin DR-60 (Class 2)

equivalent QPL-25135-listed removers

\section{Container Sizes: one-gallon cans}

case of 4 one-gallon cans

five-gallon pail

55-gallon drum

Basic Instructions: (These instructions describe the basic process, but they may be amended by the user to comply with applicable specifications and/or inspection criteria provided by the contracting agency.)

1. Application: Apply RC-88 only to clean, dry surfaces by spraying, flowing, brushing or dipping.

2. Dwell-Time: A 10 minute minimum dwell time is suggested. When particularly tight cracks are suspected, or the part is especially critical, the dwell time may be extended to 30 minutes, or longer.

revised 14 April 1993

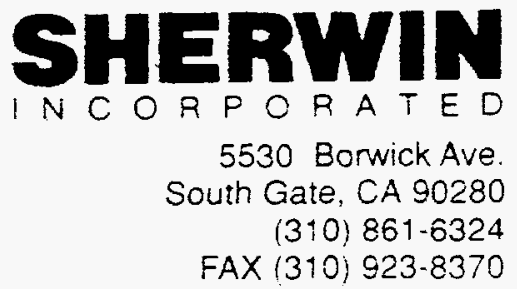


Do not soak the part. To increase sensitivity, as well as conserve material, allow the penetrant to drain from the part surface back into the penetrant tank.

3. Removal

A. Hydrophilic Dip Method

a. pre-wash: following dwell, use a plain water rinse to remove $90-99 \%$ of the undrained penetrant from surface. Use a coarse spray at 20-50 psi; use ambient temperature - not heated- water. Do not over wash.

b. immersion: immerse and agitate the part in $20-30 \%$ hydrophilic emulsifier solution. Immersion time and agitation will vary with part geometry and surface condition.

c. rinse: remove part from tank; clean with coarse, plain water spray

B. Hydrophilic Spray Method

a. wash: inject a $0.1-5.0 \%$ emulsifier solution into pressurized rinse water; spray the part. Use a coarse spray at 20-50 psi; use ambient temperature - not heated- water. Use very dilute emulsifier solutions since spraying "scrubs" the penetrant from part. Wash time and solution concentrations vary with part geometry and surface conditions.

b. rinse: use coarse plain water spray to remove all traces of emulsified penetrant.

C. Lipophilic Method

a. emulsification: dip part into undiluted lipophilic emulsifier, remove part, and allow excess emulsifier to drain back into tank. During drain time, the emulsifier will mix with surface penetrant. Parts with rough surfaces require longer drain times.

b. rinse: use coarse, plain water spray to remove all traces of emulsified penetrant.

4. Drying: A recirculating oven no higher than $160^{\circ} \mathrm{F}\left(71^{\circ} \mathrm{C}\right)$ is suggested. Leave part in oven just long enough to evaporate surface moisture. Drying is improved by using pressurized air to disperse and remove excess water before placing part in oven.

5 Developing: RC-88 is self-developing and flaw marks are usually apparent almost immediately after the part is dry. However, since RC-88 is used on critical components to find microscopic and incipient cracks, using a developer is mandatory. Sherwin D-90G or D-99A, both dry powders, are recommended for production inspection. Sherwin D-100 or D-100NF, both nonaqueous, are suggested for small areas. (Always apply nonaqueous developers in a light coat.)

\section{Applicable Specifications:}

\author{
MIL-I-25135 Rev's. D \& E \\ ASME Code NDT, Sec. $V$ \\ Navships 250-1500 \\ Lockheed \\ BAC 5423 \\ RDT-F3-6T \\ ASTM-E-165
}

\author{
Northrup \\ MIL-STD-271 E \\ AMS-3155 \\ GE-DFO \\ General Dynamics \\ Sikorsky Aircraft
}

AECL

MIL-STD 6866

AMS-2647

Garrett EMS 52309

AMS-3157

MIL-STD-2132

RC-88 lends itself to heat assisted penetrant methods, and is especially conducive to inspecting in-service parts, e.g., turbine engine parts. Write for heat assisted method particulars.

\section{PRECAUTIONARY INFORMATION}

RC-88 is a combustible liquid. Use with adequate ventilation and away from sparks, fire or open flame. Avoid prolonged or repeated contact with skin. Do not take internally. Avoid prolonged or repeated breathing of vapors. Read the label on the container for additional precautionary information. 
Material Safety Data Sheet

May used to comply with

OSHA's Hazard Cummunicalion Standard.

29 CFA 1910. $: 200$. Standara must be

consulted for specific requirements.

IOENTITY (AS LSeci on LaDeN and LSI)

DUBE-CHEK PENETRA.!'T RC:8:

\section{Sirstion 1}

Manufacturer's Name

Sherwin Incorporated

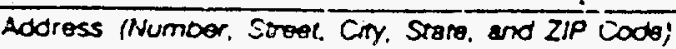

5530 Borwick Ave.

South Gate, CA 90230
U.S. Department of Labor

Occupational Safety and Health Administration

(Non-Mrillutory Form)

Forn Approved

OMIB No. 1218-0072

Note: Blank speces are not perminted. If anj irem is not applicaole. or no mtomacon is avalebie. the space must be manked to indica!e that

Transportation Emergency: CHEMTREC 800/424-9300

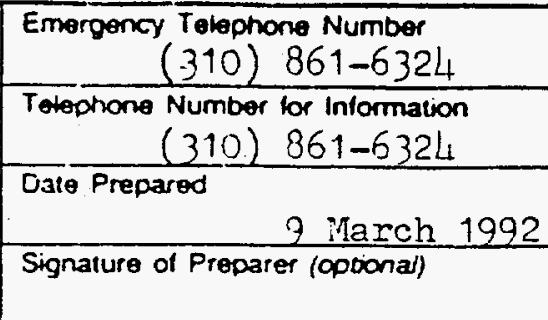

\section{Section II - Hazardous Irigredients/Identity Information}

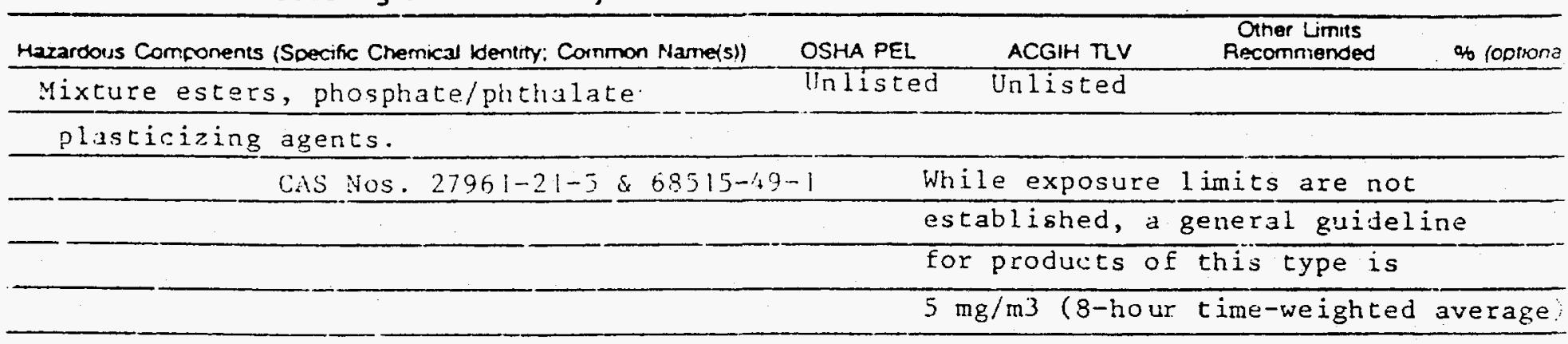

HIIIS - $F-1, E-2,3-0, S-2$

Section III - Physicai/Chernical Characteristics

\begin{tabular}{l|c|l|c|}
\hline Baling Promt & $440^{\circ} \mathrm{F}$ & Spectic Gravty $\left(\mathrm{H}_{2} \mathrm{O}-1\right)$ & 0.9050 \\
\hline Vapor Pressure :mm Hg.) & N/A & Melling Pant & N/A \\
\hline Vador Density (AIR - 1) & N/A & $\begin{array}{l}\text { Evaporation Rate } \\
\text { (Butri Acrate - 1) }\end{array}$ & N/A \\
\hline
\end{tabular}

Solubuity in Water

Not soluble, slightly miscible

Appearance and Cos

Yellow, green liquid.

Petroleum Odor

\section{Section IV - Fire and Explosion Hazard Data}

\begin{tabular}{|c|c|c|c|c|c|}
\hline Fash Pant (Method Used) & $200^{\circ} \mathrm{F}$ & ASTi1 093 & $\begin{array}{r}\text { Flammabls imnts } \\
\text { unknown }\end{array}$ & LEL $\quad N / A$ & UEL $\mathrm{N} / \mathrm{A}$ \\
\hline
\end{tabular}

Extinglushing Media

$$
\mathrm{CO}-2 \quad \text { Foan: }
$$

Dry Chemica!

Soecial Fire Fighting Procecures

Do rat use direct stream of water; it spreads the fire. Product

may float and reignice on surface of water.

Unusual Fire and Explosion Hazards

Ot buraing, chis product can release toxic fumes and vapors. Firefighters should weat self-contained breathing apparatus and full protective clothing. 
Soctlon V - Reactivity Data

\begin{tabular}{l|l}
\hline Senority & Uneteble \\
\cline { 2 - 2 } & STede \\
\hline
\end{tabular}

\begin{tabular}{|l|l|}
\hline $\cos x$ \\
\hline$x$
\end{tabular}

oxidizing materiala.

incompatioflily (Marerials to Anolor)

Hezandous Decomposition or Oproncucts

Carbon monoxide and other unidentified organic compunds may be found upon combustion.

Herardoens

Poprmerization

\begin{tabular}{|l|l|l|}
\hline Mar Docer & & Con \\
\hline Win Nol Oocu: & $\times$ & \\
\hline
\end{tabular}

Section VI - Health Hazard Data

Roune(s) of Entry.

Primary rouces of entry

Condition 10 Anoid

Open flameg

1 hazerds normally incompatible

oils

with petrole

Hnath Hazards (Acuto and Civonic)

Not known

Carcinogenncity

NTP?

Ne)

WAC Monographs?

NO

OStu Raguiated? No

Signs and Symptorrs of Exposure

Eyes - severe irritation. Skin - Irritation. Inhalation - light headiness.

Medical Conditions

Generaly Aograveted by Exposure Unknown

Emergency and Firs Aid Procedures

Eyes-flush with water...Skin-Wash, remove centaminated clotbing Labalation-Eresh Air

Ingegtion-Do not iuduce vomiting. Eyes \&.Ingestion-Medical Atfention Essential.

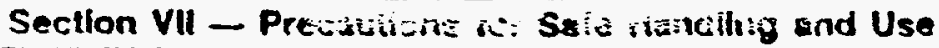

Sieps to 6 : Fiken in Ce $\rightarrow$ Ietgra! ! Tolased : Foilled

Fxtinguish all flames. Make dike.

Wasta Diepoed Matho:

Take up with an absorbent material and dispose of in compliance with all

local, state and federal regulations.

Precautions to be Taken in Hersiting and Storing

Handling - do not splash or create mists or vapors.

Storage - Store away from high temperatures and open flames. Keep containers closed.

Oher Precautions Emptie: container retaina vapor and product reaidues. Do not cut or weld

on or near this container.

\section{Sectlon VIII - Control Messures}

Pespiration Protectun (Specily Trpo)

Use NIOSH-approved respirator if vapors or mists are generated.

Vortiletion

$$
\begin{aligned}
& \text { Local Extar Advisable. } \\
& \text { Mocharicy fomery not necessary. }
\end{aligned}
$$

Chemical resistant

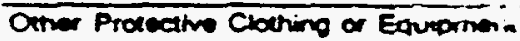

Workertrolionic Practicas

Wash before eating. Do not smoke.

\begin{tabular}{|ll}
\hline Sonciel & none \\
Orner none &
\end{tabular}
Ero Proction
Chemical Safety when possibility of splash: 


\section{ER-83A HYDROPHILIC EMULSIFIER}

Approved Method D, Type I, MIL-J-25135 Rev. D

Approved Group V \& VI, MIL-1-25135 Rev. C

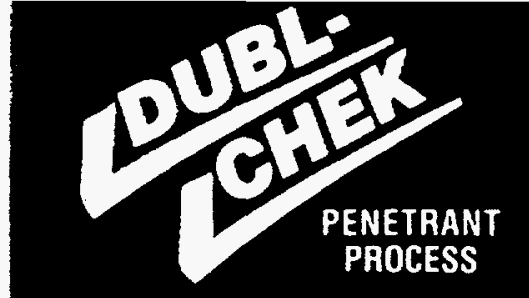

Description: ER-83A is a concentrated "detergent" used diluted with water to emulsify Sherwin's fluorescent penetrants, such as the company's "RC-" designated products. ER-83A removes surface, non-water-washable penetrants by spray or immersion following a pre-wash step. The product meets low-sulfur, low-halogen, and low-sodium requirements, has a flash point over $200^{\circ} \mathrm{F}$, and is an OSHA Class IIIB material.

Speclal Features: ER-83A is low in solvent properties and relies primarily on surfactants (surface active agents) for its removal action. This minimizes the risk of "over-emulsification," or dissolving of flaw-entrapped penetrant, due to extended emulsifier dwell times, or to over concentration arising from water evaporation.

ER-83A works well on smooth or rough surfaces as well as on machined or coated surfaces.

\section{Companion Materials:}

$\begin{array}{ll}\text { Penetrants - } & \text { Sherwin RC-29 } \\ \text { Sherwin RC-50 } \\ \text { Sherwin RC-65 } \\ \text { Sherwin RC-77 }\end{array}$

Developers - Sherwin D-90G Dry Powder (form a)

Sherwin D-100 Nonaqueous (form d)

Sherwin D-100NF Nonaqueous (form d)

Sherwin D-113G Water Soluble (form b)

equivalent QPL-25135 developers

$\begin{array}{ll}\text { Container Sizes: } & \begin{array}{l}\text { one-gallon cans } \\ \text { case of } 4 \text { one-gallon cans } \\ \text { five-gallon pail } \\ \text { 55-gallon drum }\end{array}\end{array}$

Basic Instructions: (These instructions describe the basic process. They may need to be amended by the user to comply with applicable specifications and/or inspection criteria provided by the contracting agency.)

There are two ways to apply ER-83A: by direct spraying or by immersing the part in a diluted emulsifier solution. Either method is employed after the part has been drained of as much penetrant as possible and has undergone a pre-wash step. Pre-washing removes most excess, undrained penetrant, thereby permitting lower strength solutions and shorter dwell times as well as reducing penetrant carfy-over to the emulsifier tank.

Pre-wash Step: Once the penetrant dwell and drain step is complete, and prior to applying the ER-83A solution, spray the part at an angle with plain, ambient temperature water to mechanically remove ninety to ninety-nine percent of the remaining surface penetrant. Do not use hot water. A course spray of $20-40$ p.s.i. is preferred. Perform this operation under black light to insure that only a microscopic film of penetrant continues to adhere to the part surface before spraying or immersing the part in the emulsifier solution. Do not over wash.

Spray Application: Use very dilute solutions when spraying ER-83A Emulsifier, since spraying in itself helps remove the penetrant. The solution strength, which may vary from as low as $0.1 \%$ to as high as $5.0 \%$ is regulated by several factors: (1) pre-wash thoroughness, (2) surface texture, (3) force of the spray, and (4) solution contact time during and following spray application. A solution strength less than $0.2 \%$ (i.e., 1 part emulsifier to 500 parts water) may suffice for parts having smooth surfaces, even when using a brief spray cycle.

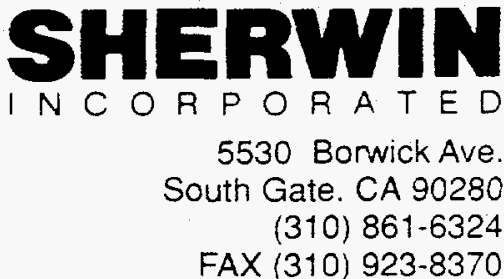


Maintaining the strength of ER-83A spray solution is not as critical as with competitive hydrophilic emulsifiers which rely on solvent action; nevertheless, in order to minimize over-emulsitying, an upper concentration limit should be established and the solution checked regularly with a refractometer. Excess foaming indicates increased solution concentration.

For economy as well as maximum sensitivity, use the lowest strength solution that is consistent with reasonably brief application time. Excessive background flourescence or the need for prolonged spraying indicate the need to increase the solution strength.

Prolonged water scrubbing, with or without emulsifier, can erode penetrant from wide flaws. If possible, the emulsifier should be rinsed under black light to insure against over-washing.

Immersion Appllcation: The immersion technique for applying ER-83A requires a stronger solution - $20 \%$ to $30 \%-$ than the spray technique. On particularly difficult parts, accelerate the solution's action with mild agitation by moving the parts up and down in the solution or by using devices such as mixers or air stirrers.

A thorough, clear-water rinse follows the immersion. An inadequate final rinse will interfere with developer action; emulsifier solution should not be allowed to dry on the surface.

Use a refractometer to monitor the ER-83A solution for evaporative water loss, which can occur rapidly in hot, dry conditions. Water loss leads to an over-active emulsifier solution. Restore proper solution strength by simply adding water.

The ER-83A solution must also be monitored for penetrant contamination. While the pre-wash step minimizes carrying penetrant to the solution tank, eventually penetrant contamination will require recharging the solution tank.

\section{Applicable Specifications:}

\author{
MIL-I-25135 Rev's. C \& D \\ ASME B \& P Vessel Code \\ Navships 250-1500 \\ Lockheed \\ BAC 5423 \\ MIL-STD-2132 \\ MTU \\ Snecma
}

\author{
Allison Gas Turbine \\ MIL-STD-271 E \\ AMS-2647 \\ AMS-3157 \\ General Dynamics \\ ASTM-E-165 \\ Rolls Royce \\ Sikorsky
}

\author{
AECL \\ MIL-STD 6866 \\ RDT-F3-6T \\ Garrett EMS 52309 \\ Northrup \\ General Dynamics \\ $P \& W F P M$ \\ GE-DFO
}

\section{PRECAUTIONARY INFORMATION}

ER-83A is a combustible liquid as supplied. Use with adequate ventilation and away from sparks, fire or open flame. Avoid prolonged or repeated contact with skin. Do not take internally. Avoid prolonged or repeated breathing of vapors. Highly Detergent. DANGER! Causes eye burns. First Ald: flush eyes with water; call a physician. Read the label on the container for additional precautionary information. 
Material Safety Data Sheet

May be used to comply with

OSHA's Hazard Communication Standard.

29 CFA 1910.1200. Standard must be

consulted lor specific requirements.

IOENTITY (AS Used on Label and LSt)

Sherwin Dubl-Chek Emulsifier ER83A

\section{Section 1}

Manutacturef's Name

Sherwin Incorporated

Address (Number. Streot. City, Stare, and ZIP Codo)

5530 Borwick Ave.

South Gate, CA 90280
U.S. Department of Labor

Occupational Safety and Health Administration

(Non-Mandatory Form)

Form Approved

OMB No. 1218-0072

Note: Blank saaces are not permitred. If any item is not applicable, of no informaton is avalable, the space must be marked to mdica'e that.

Transporation Emergency: CHEMTREC 800/424-9300

Emergency Telephone Number

$$
\text { (310) 861-6324 }
$$

Telephone Number lor Information

Date Prepared

(310) $861-6324$

9 Warch 1992

Signalure of Preparer (optional)

\section{Section 11 - Hazandous Ingredients/dentity Information}

Mazardous Components (Specific Chemical identity: Common Name(s))
Hexylene Glycol
CAS No. 107-41-5

OSHA PEL

ACGIH TLV

Orner Limits

Recommended

\% foptiona:

$25 \mathrm{ppm} \quad 25 \mathrm{ppm}$

(ceiling limit) (ceiling limit)

ACGIH states: "In order to prevent eye irritation

it is reconmended that the ceiling 1 imit of $25 \mathrm{ppm}$

be adopted."

HIIS - F-1, $E-2, R-0, S-0$

Section III - Physical/Chemical Characteristics

\begin{tabular}{|c|c|c|c|}
\hline Boling Point & $390^{\circ} \mathrm{F}$ & Soecific Gravity $\left(\mathrm{H}_{2} \mathrm{O}=1\right)$ & 0.98 \\
\hline $\begin{array}{l}\text { Vapor Pressure (mm Hg.) } \\
\text { not volatile }\end{array}$ & $<.1$ & Mething Pont & $N / A$ \\
\hline Vapor Density (AIR $=1$ ) & 4 & $\begin{array}{l}\text { Evaporation Rate } \\
\text { (Buty Acetate }-1 \text { ) not volatile }\end{array}$ & $N / A$ \\
\hline
\end{tabular}

Solubility in Water

completely soluble

Appearance and Ocor

pink liquid, detergent odor

Section IV - Fire and Explosion Hazard Data

Flash Pant (Method Used) $>200^{\circ} \mathrm{F}$ ASTM D 93

Exinguishing Media

Flammable Limits

unkno:sn.

\begin{tabular}{|l|l|l|l}
\hline LE: & UEL & N/A \\
\hline
\end{tabular}

CO-2 Eoam Dry Chemical

Spectal Fire Fighting Procedures

Do not use direct stream of water. It spreads the fire.

Firefighters should wear self-contained breathing apparatus and full protective clotining. Unusual Fire and Exolosion Hazards

On burning, this product can release toxic fumes and vapors. 
Section V - Roactivity Data

Stabulity

Unstablo

Siablo

Incompatlbillty (Materials to Avolol

Hazardous Decomposition or Byproducts

liarbon monoxide and other

Hazardous

Polymerization

\begin{tabular}{|l|l|}
\hline May Oocur & \\
\hline Will Nor Occur & $\mathrm{X}$ \\
\hline
\end{tabular}

Section VI - Health Hazard Data

Poute(s) of Eniry: Innalation?

Primary routes of entry skin and eye contact.

Skin?

Oxidizing materials.

Open flames and hazards normally incompatible with petroleum oils

Health Hazards (Acure and Chronic)

Not known

Carcinogenicity

NTP?

$N=$

IARC Monographs?

No

OSHA Rogulated? NO

Signs and Symptoms of Exposure

Eyes - severe irritation. Skin - Irritation. Inhalation - light headiness.

Medical Conditions

Generally Aggravaled by Exposure Unknown

\section{Emergency and First Aid Procedures}

Eyes-flush with water. Skin- Wash, remove contaminated clothing Inhalation-Eresh Air

Ingestion-Do not induce vomiting. Eyes \&ingestion - Medical Attention Essential.

Section VII - Precautions for Safe Handling and Use

Sieps to be Taken in Case Material is Released or Spilled

$$
\text { Extinguish all flames. Make dike. }
$$

\section{Waste Disposal Method}

Take up with an absorbent material and dispose of in compliance with all

local, state and federal regulations.

Precautions 10 Be Taken in Handling and Storing

Handling - do not splash or create mists or vapors.

Storage - Store away from high temperatures and open flames. Keep containers closed.

OTher Precautions

Emptied container retains vapor and product residues. Do not cut or weld

on or near this container.

\section{Section VIII - Control Measures}

Pessouraion Procectum (Spocity Trpe)

Use NIOSH-approved respirator if vapors or mists are generaced. 
Appendix B: List of Dye Penetrant Suppliers

The following is a list of manufacturers of fluorescent penetrant materials as listed on the U.S. Miletory QPL-25135-17, Feb. 1995.

1. American Gas and Chemical Co. Ltd. 220 Pegasus Ave., Northvale, NJ 07647

2. Ardrox Inc.

16961 Knott Ave., LaMiranda, CA 90638

3. Chem-Trend Inc.

1445 W. McPherson Park Drive, Howell, MI 48844-0860

4. Magneflux Division of Illinois Tool Works

7301 W. Ainslie Ave., Harwood Heights, IL 60656

5. Met-L-Chek

1639 Euclid St., Santa Monica, CA 90404

6. Sherwin Inc.

5530 Borwick Ave., South Gate, CA 90280-7402

7. Turco Products Inc.

PO Box 272, Avon, NJ 07717 


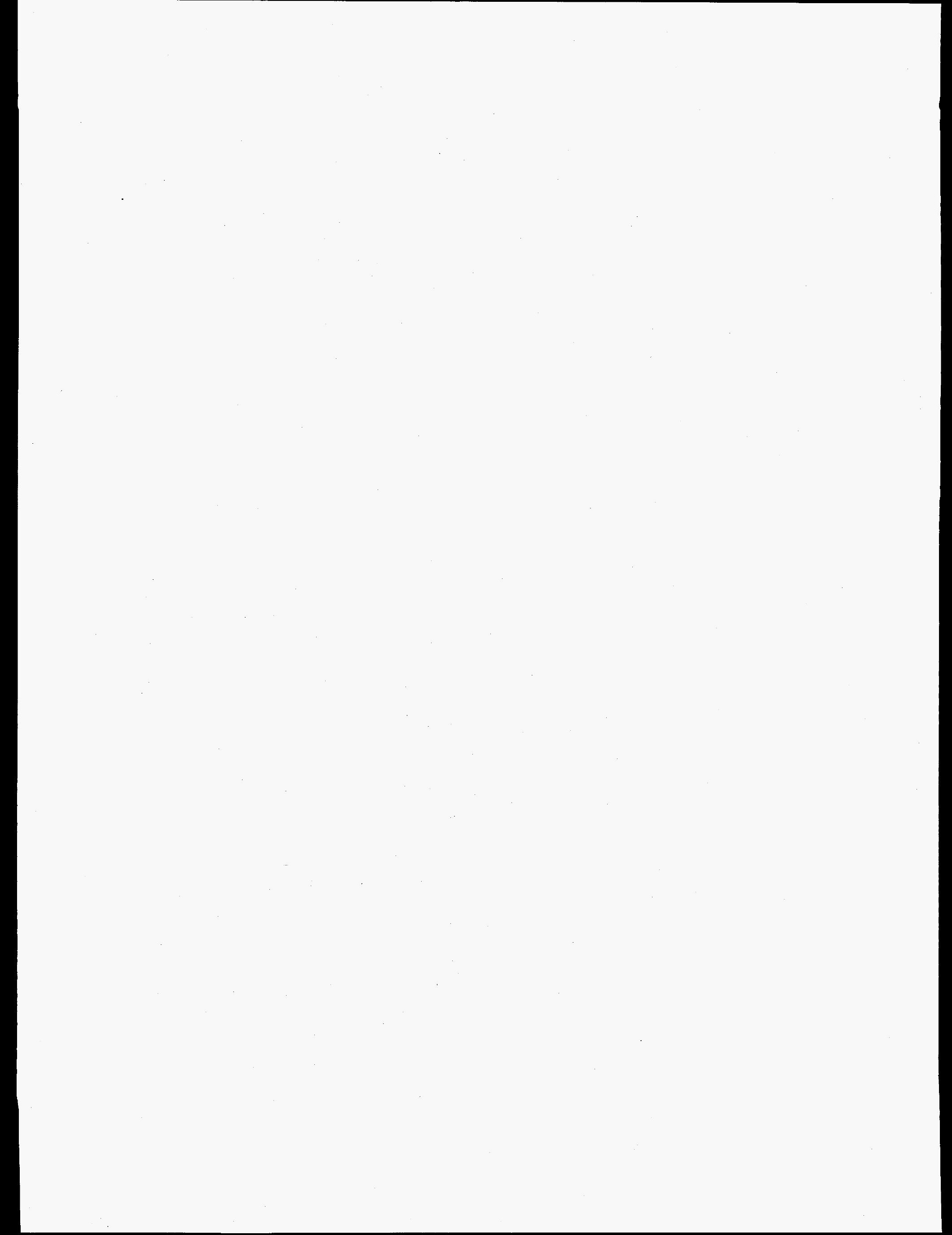




\section{INTERNAL DISTRIBUTION}

Central Research Library (2)

Document Reference Section

Laboratory Records Department (2)

Laboratory Records, ORNL RC

ORNL Patent Section

M\&C Records Office (3)

L. F. Allard, Jr.

L. D. Armstrong

P. F. Becher

R. F. Bernal

T. M. Besmann

P. J. Blau

R. A. Bradley

K. Breder

C. R. Brinkman

V. R. Bullington

G. M. Caton

S. J. Chang

A. Choudhury

D. D. Conger

R. H. Cooper, Jr.

S. A. David

J. L. Ding

M. K. Ferber

R. L. Graves

D. L. Greene

H. W. Hayden, Jr.

E. E. Hoffman

C. R. Hubbard
M. A. Janney

D. R. Johnson (5)

D. Joslin

R. R. Judkins

M. A. Karnitz

B. L. Keyes

H. D. Kimrey, Jr.

W. Y. Lee

K. C. Liu

E. L. Long, Jr.

W. D. Manly

R. W. McClung

D. J. McGuire

T. A. Nolan

A. E. Pasto

K. P. Plucknett

M. H. Rawlins

M. L. Santella

A. C. Schaffhauser

E. J. Soderstrom

D. P. Stinton

R. W. Swindeman

T. N. Tiegs

B. H. West

S. G. Winslow

J. M. Wyrick 


\section{EXTERNAL DISTRIBUTION}

Pioneering Research Info. Ctr. E.I. Dupont de Nemours \& Co. Experimental Station

P.O. Box 80302

Wilmington DE 19880-0302

Jeffrey Abboud

U.S. Advanced Ceramics Assoc. 1600 Wilson Blvd., Suite 1008

Arlington VA 22209

James H. Adair

University of Florida

Materials Science \& Engineering 317 MAE Bldg.

Gainesville FL 32611-2066

Donald F. Adams

University of Wyoming

Mechanical Engineering Dept.

P.O. Box 3295

Laramie WY 82071

Andrzej Aeamski

Materials Conversion Group

236-B Egidi Drive

Wheeling IL 60090

Jalees Ahmad

AdTech Systems Research Inc.

Solid Mechanics

1342 N. Fairfield Road

Dayton OH 45432-2698

Yoshio Akimune

NISSAN Motor Co., Ltd.

Materials Research Laboratory

1 Natsushima-Cho

Yokosuka 237

JAPAN

Mufit Akinc

Iowa State University

322 Spedding Hall

Ames IA 50011
Ilhan A. Aksay

Princeton University

A313 Engineering Quadrangle

Princeton NJ 08544-5263

Charles Aldridge

Heany Industries, Inc.

249 Briarwood Lane

Scottsville NY 14546

Joseph E. Amaral

Instron Corporation

Corporate Engineering Office

100 Royale Street

Canton MA 02021

Edward M. Anderson

Aluminum Company of America

N. American Industrial Chemical

P.O. Box 300

Bauxite AR 72011

Norman C. Anderson

Ceradyne, Inc.

Ceramic-to-Metal Division

3169 Redhill Avenue

Costa Mesa CA 92626

Don Anson

BCL

Thermal Power Systems

505 King Avenue

Columbus OH 43201-2693

Thomas Arbanas

G.B.C. Materials Corporation

580 Monastery Drive

Latrobe PA 15650-2698

Frank Armatis

3M Company

Building 60-1N-01

St. Paul MN 55144-1000 
Everett B. Arnold

Detroit Diesel Corporation

Mechanical Systems Technology

13400 Outer Drive West

Detroit MI 48239-4001

Bertil Aronsson

Sandvik AB

S-12680

Stockholm Lerkrogsvagen 19

SWEDEN

Dennis Assanis

University of Michigan

Dept. of Mechanical Engineering 321 W.E. Lay, N.C.

Ann Arbor MI 48109

V. S. Avva

North Carolina A\&T State Univ.

Dept. of Mechanical Engineering

Greensboro NC 27411

Patrick Badgley

Sky Technologies, Inc.

2815 Franklin Drive

Columbus IN 47201

Sunggi Baik

Pohang Institute Sci. \& Tech.

P.O. Box 125

Pohang 790-600

KOREA

John M. Bailey

Consultant

Caterpillar, Inc.

P.O. Box 1875

Peoria IL 61656-1875

Bob Baker

Ceradyne, Inc.

3169 Redhill Avenue

Costa Mesa CA 92626

Frank Baker

Aluminum Company of America

Alcoa Technical Center

Alcoa Center PA 15069
Clifford P. Ballard

AlliedSignal Aerospace Company

Ceramics Program

P.O. Box 1021

Morristown NJ 07962-1021

B. P. Bandyopadhyay

ELID Team

Wako Campus

2-1 Hirosawa Wako-shi

Saitama 351-01

JAPAN

P. M. Barnard

Ruston Gas Turbines Limited

P.O. Box 1

Lincoln LN2 5DJ

ENGLAND

Harold N. Barr

Hittman Corporation

9190 Red Branch Road

Columbia MD 21045

Renald D. Bartoe

Vesuvius McDanel

510 Ninth Avenue

Box 560

Beaver Falls PA 15010-0560

David L. Baty

Babcock \& Wilcox - LRC

P.O. Box 11165

Lynchburg VA 24506-1165

Donald F. Baxter, Jr.

ASM International

Advanced Materials \& Processes

Materials Park OH 44073-0002

M. Brad Beardsley

Caterpillar Inc.

Technical Center Bldg. E

P.O. Box 1875

Peoria IL 61656-1875 
John C. Bell

Shell Research Limited

Thornton Research Centre

P.O. Box 1

Chester $\mathrm{CH} 13 \mathrm{SH}$

ENGLAND

Larry D. Bentsen

BFGoodrich Company

R\&D Center

9921 Brecksville Road

Brecksville OH 44141

Tom Bernecki

Northwestern University

1801 Maple Avenue

Evanston IL 60201-3135

Charles F. Bersch

Institute for Defense Analyses

1801 N. Beauregard Street

Alexandria VA 22311

Ram Bhatt

NASA Lewis Research Center

21000 Brookpark Road

Cleveland $\mathrm{OH} 44135$

Deane I. Biehler

Caterpillar Inc.

Engineering Research Materials

P.O. Box 1875, Bldg. E

Peoria IL 61656-1875

William D. Bjorndahl

TRW, Inc.

One Space Park, MS:R6-2188

Building 01, Room 2040

Redondo Beach CA 90278

Keith A. Blakely

Advanced Refractory Technologies, Inc.

699 Hertel Avenue

Buffalo NY 14207

Edward G. Blanchard

Netzsch Inc.

119 Pickering Way

Exton PA 19341
Bruce Boardman

Deere \& Company Technical Ctr.

3300 River Drive

Moline IL 61265

Lawrence P. Boesch

EER Systems Corp.

1593 Spring Hill Road

Vienna VA 22182-2239

Donald $\mathbf{H}$. Boone

Boone \& Associates

2412 Cascade Drive

Walnut Creek CA 94598-4313

Tom Booth

AlliedSignal, Inc.

AiResearch Los Angeles Division

2525 West 190th Street

Torrance CA 90509-2960

Raj Bordia

University of Washington

Roberts Hall

Box 35212

Seattle WA 98195-2120

Tibor Bornemisza

Energy Technologies Applications, Inc.

5064 Caminito Vista Lujo

San Diego CA 92130-2846

J.A.M. Boulet

University of Tennessee

Engineering Science \& Mechanics

Knoxville TN 37996-2030

Leslie J. Bowen

Materials Systems

53 Hillcrest Road

Concord MA 01742

Steven C. Boyce

Air Force Office of Scientific

Research

AFOSR/NA Bldg. 410

Bolling AFB DC 20332-6448 
Steve Bradley

UOP Research Center

50 E. Algonquin Road

Des Plaines IL 60017-6187

Michael C. Brands

Cummins Engine Company, Inc.

P.O. Box 3005, Mail Code 50179

Columbus IN 47201

Raymond J. Bratton

Westinghouse Science \& Technology

1310 Beulah Road

Pittsburgh PA 15235

John J. Brennan

United Technologies Corporation

Silver Lane, MS:24

East Hartford CT 06108

Terrence K. Brog

Golden Technologies Company

4545 McIntyre Street

Golden CO 80403

Gunnar Broman

317 Fairlane Drive

Spartanburg SC 29302

Alan Brown

P.O. Box 882

Dayton NJ 08810

Jesse J. Brown

VPI \& SU

Ctr. for Adv. Ceram. Mater.

Blacksburg VA 24061-0256

Sherman D. Brown

University of Illinois

Materials Science \& Engineering

105 South Goodwin Avenue

Urbana IL 61801

S. L. Bruner

Ceramatec, Inc.

2425 South 900 West

Salt Lake City UT 84119
Walter Bryzik

U.S. Army Tank Automotive

Command

R\&D Center, Propulsion Systems

Warren MI 48397-5000

Curt V. Burkland

AMERCOM, Inc.

8928 Fullbright Avenue

Chatsworth CA 91311

Bill Bustamante

AMERCOM, Inc.

8928 Fullbright Avenue

Chatsworth CA 91311

Oral Buyukozturk

Massachusetts Institute of

Technology

77 Massachusetts Ave., Rm 1-280

Cambridge MA 02139

David A. Caillet

Ethyl Corporation

451 Florida Street

Baton Rouge La 70801

Roger Cannon

Rutgers University

P.O. Box 909

Piscataway NJ 08855-0909

Scott Cannon

P.O. Box 567254

Atlanta GA 30356

Harry W. Carpenter

1844 Fuerte Street

Fallbrook CA 92028

David Carruthers

Kyocera Industrial Ceramics

P.O. Box 2279

Vancouver WA 98668-2279

Calvin H. Carter, Jr.

Cree Research, Inc.

2810 Meridian Parkway

Durham NC 27713 
J. David Casey

35 Atlantis Street

West Roxbury MA 02132

Jere G. Castor

J. C. Enterprise

5078 N. 83rd Street

Scottsdale AZ 85250

James D. Cawley

Case Western Reserve University

Materials Science \& Engineering

Cleveland $\mathrm{OH} 44106$

Thomas C. Chadwick

Den-Mat Corporation

P.O. Box 1729

Santa Maria CA 93456

Ronald H. Chand

Chand Kare Technical Ceramics

2 Coppage Drive

Worcester MA 01603-1252

William Chapman

Williams International Corp.

2280 W. Maple Road

Walled Lake MI 48390-0200

Ching-Fong Chen

LECO Corporation

3000 Lakeview Avenue

St. Joseph MI 49085

William J. Chmura

Torrington Company

59 Field Street

Torrington CT 06790-4942

Tsu-Wei Chou

University of Delaware

201 Spencer Laboratory

Newark DE 19716

R. J. Christopher

Ricardo Consulting Engineers

Bridge Works

Shoreham-By-Sea W. Sussex

BN435FG ENGLAND
Joel P. Clark

Massachusetts Institute of

Technology

Room 8-409

Cambridge MA 02139

Giorgio Clarotti

Commission of the European Comm

DGXII-C3, MO75, 1-53;

200 Rue de la Loi

B-1049 Brussels

BELGIUM

W. J. Clegg

ICI Advanced Materials

P.O. Box 11, The Heath

Runcorn Cheshire WA7 4QE

ENGLAND

William S. Coblenz

Adv. Research Projects Agency

3701 N. Fairfax Drive

Arlington VA 22203

Gloria M. Collins

ASTM

1916 Race Street

Philadelphia PA 19103

William C. Connors

Sundstrand Aviation Operations

Materials Science \& Engineering

4747 Harrison Avenue

Rockford IL 61125-7002

John A. Coppola

Carborundum Company

Niagara Falls R\&D Center

P.O. Box 832

Niagara Falls NY 14302

Normand D. Corbin

Norton Company

SGNICC/NRDC

Goddard Road

Northboro MA 01532-1545 
Douglas Corey

AlliedSignal, Inc.

2525 West 190th Street, MS:T52

Torrance CA 90504-6099

Keith P. Costello

Chand/Kare Technical Ceramics

2 Coppage Drive

Worcester MA 01603-1252

Ed L. Courtright

Pacific Northwest Laboratory

MS:K3-59

Richland WA 99352

Anna Cox

Mitchell Market Reports

P.O. Box 23

Monmouth Gwent NP5 4YG

UNITED KINGDOM

J. Wesley Cox

BIRL

1801 Maple Avenue

Evanston IL 60201-3135

Art Cozens

Instron Corporation

3414 Snowden Avenue

Long Beach CA 90808

Mark Crawford

New Technology Week

4604 Monterey Drive

Annandale VA 22003

Richard A. Cree

Markets \& Products, Inc.

P.O. Box 14328

Columbus $\mathrm{OH} 43214-0328$

Les Crittenden

Vesuvius McDanel

Box 560

Beaver Falls PA 15010

M. J. Cronin

Mechanical Technology, Inc.

968 Albany-Shaker Road

Latham NY 12110
Gary M. Crosbie

Ford Motor Company

20000 Rotunda Drive

MD-2313, SRL Building

Dearborn MI 48121-2053

Floyd W. Crouse, Jr.

U.S. Department of Energy

Morgantown Energy Tech. Ctr.

P.O. Box 880

Morgantown WV 26505

John Cuccio

AlliedSignal Engines

P.O. Box 52180, MS:1302-2Q

Phoenix AZ 85072-2180

Raymond A. Cutler

Ceramatec, Inc.

2425 South 900 West

Salt Lake City UT 84119

Stephen C. Danforth

Rutgers University

P.O. Box 909

Piscataway NJ 08855-0909

Sankar Das Gupta

Electrofuel Manufacturing Co.

9 Hanna Avenue

Toronto Ontario MGK-1W8

CANADA

Frank Davis

AlliedSignal Aerospace Company

7550 Lucerne Drive, \#203

Middleburg Heights OH 44130

Robert F. Davis

North Carolina State University

Materials Engineering Department

P.O. Box 7907

Raleigh NC 27695

George C. DeBell

Ford Motor Company

Scientific Research Lab

P.O. Box 2053, Room S2023

Dearborn MI 48121-2053 
Michael DeLuca

RSA Research Group

1534 Claas Ave.

Holbrook NY 11741

Gerald L. DePoorter

Colorado School of Mines

Metallurgical \& Materials Engr

Golden CO 80401

J. F. DeRidder

Omni Electro Motive, Inc.

12 Seely Hill Road

Newfield NY 14867

Nick C. Dellow

Materials Technology Publications

40 Sotheron Road

Watford Herts WD1 2QA

UNITED KINGDOM

L. R. Dharani

University of Missouri-Rolla

224 M.E.

Rolla MO 65401

Douglas A. Dickerson

Union Carbide Specialty Powders

1555 Main Street

Indianapolis IN 46224

John Dodsworth

Vesuvius Research \& Development

Technical Ceramics Group

Box 560

Beaver Falls PA 15010

B. Dogan

Institut fur Werkstofforschung

GKSS-Forschungszentrum Geesthacht

Max-Planck-Strasse

D-2054 Geesthacht

GERMANY

Alan Dragoo

U.S. Department of Energy

ER-131, MS:F-240

Washington DC 20817
Jean-Marie Drapier

FN Moteurs S.A.

Material and Processing

B-4041 Milmort (Herstal)

BELGIUM

Kenneth C. Dreitlein

United Technologies Res. Ctr.

Silver Lane

East Hartford CT 06108

Robin A.L. Drew

McGill University

3450 University Street

Montreal Quebec H3A 2A7

CANADA

Winston H. Duckworth

BCL

Columbus Division

505 King Avenue

Columbus OH 43201-2693

Ernest J. Duwell

3M Abrasive Systems Division

3M Center

St. Paul MN 55144-1000

Chuck J. Dziedzic

GTC Process Forming Systems

4545 McIntyre Street

Golden CO 80403

Robert J. Eagan

Sandia National Laboratories

Engineered Mater. \& Proc.

P.O. Box 5800

Albuquerque NM 87185-5800

Harry E. Eaton

United Technologies Corporation

Silver Lane

East Hartford CT 06108

Harvill C. Eaton

Louisiana State University

240 Thomas Boyd Hall

Baton Rouge LA 70803 
J. J. Eberhardt

U.S. Department of Energy

Office of Transportation Mater.

CE-34, Forrestal Building

Washington DC 20585

Jim Edler

Eaton Corporation

26201 Northwestern Highway

P.O. Box 766

Southfield MI 48037

G. A. Eisman

Dow Chemical Company

Ceramics and Advanced Materials

52 Building

Midland MI 48667

William A. Ellingson

Argonne National Laboratory

Energy Technology Division

9700 S. Cass Avenue

Argonne IL 60439

Anita Kaye M. Ellis

Machined Ceramics

629 N. Graham Street

Bowling Green KY 42101

Glen B. Engle

Nuclear \& Aerospace Materials

16716 Martincoit Road

Poway CA 92064

Kenneth A. Epstein

Dow Chemical Company

2030 Building

Midland MI 48674

Art Erdemir

Argonne National Laboratory

9700 S. Cass Avenue

Argonne IL 60439

E. M. Erwin

Lubrizol Corporation

17710 Riverside Drive

Lakewood OH 44107
John N. Eustis

U.S. Department of Energy

Industrial Energy Efficiency

CE-221, Forrestal Building

Washington DC 20585

W. L. Everitt

Kyocera International, Inc.

8611 Balboa Avenue

San Diego CA 92123

Gordon Q. Evison

332 S. Michigan Avenue

Suite 1730

Chicago IL 60604

John W. Fairbanks

U.S. Department of Energy

Office of Propulsion Systems

CE-322, Forrestal Building

Washington DC 20585

Tim Fawcett

Dow Chemical Company

Advanced Ceramics Laboratory

1776 Building

Midland MI 48674

Robert W. Fawley

Sundstrand Power Systems

Div. of Sundstrand Corporation

P.O. Box 85757

San Diego CA 92186-5757

Jeff T. Fenton

Vista Chemical Company

900 Threadneedle

Houston TX 77079

Larry Ferrell

Babcock \& Wilcox

Old Forest Road

Lynchburg VA 24505

Raymond R. Fessler

BIRL

1801 Maple Avenue

Evanston IL 60201 
Ross F. Firestone

Ross Firestone Company

188 Mary Street

Winnetka IL 60093-1520

Sharon L. Fletcher

Arthur D. Little, Inc.

15 Acorn Park

Cambridge MA 02140-2390

Michael Foley

Norton Company

Goddard Road

Northboro MA 01532-2527

Thomas F. Foltz

Textron Specialty Materials

2 Industrial Avenue

Lowell MA 01851

Renee G. Ford

Materials and Processing Report

P.O. Box 72

Harrison NY 10528

John Formica

Supermaterials

2020 Lakeside Avenue

Cleveland $\mathrm{OH} 44114$

Edwin Frame

Southwest Research Institute

P.O. Drawer 28510

San Antonio TX 78284

Armanet Francois

French Scientific Mission 4101 Reservoir Road, N.W.

Washington DC 20007-2176

R. G. Frank

Technology Assessment Group

10793 Bentley Pass Lane

Loveland $\mathrm{OH} 45140$

David J. Franus

Forecast International

22 Commerce Road

Newtown CT 06470
Marc R. Freedman

NASA Lewis Research Center

21000 Brookpark Road, MS:49-3

Cleveland $\mathrm{OH} 44135$

Douglas Freitag

Bayside Materials Technology

17 Rocky Glen Court

Brookeville MD 20833

Brian R.T. Frost

Argonne National Laboratory

9700 S. Cass Avenue, Bldg. 900

Argonne IL 60439

Lawrence R. Frost

Instron Corporation

100 Royall Street

Canton MA 02021

Xiren Fu

Shanghai Institute of Ceramics

1295 Ding-xi Road

Shanghai 200050

CHINA

J. P. Gallagher

University of Dayton Research

Institute

300 College Park, JPC-250

Dayton OH 45469-0120

Garry Garvey

Golden Technologies Company

4545 McIntyre Street

Golden CO 80403

Richard Gates

NIST

Materials Bldg., A-256

Gaithersburg MD 20899

L. J. Gauckler

ETH-Zurich

Sonneggstrasse 5

CH-8092 Zurich 8092

SWITZERLAND 
D. Gerster

CEA-DCOM

33 Rue De La Federation

Paris 75015

FRANCE

John Ghinazzi

Coors Technical Ceramics Co.

1100 Commerce Park Drive

Oak Ridge TN 37830

Robert Giddings

General Electric Company

P.O. Box 8

Schenectady NY 12301

A. M. Glaeser

University of California

Lawrence Berkeley Laboratory

Hearst Mining Building

Berkeley CA 94720

Joseph W. Glatz

510 Rocksville Road

Holland PA 18966

W. M. Goldberger

Superior Graphite Company

R\&D

2175 E. Broad Street

Columbus OH 43209

Allan E. Goldman

U.S. Graphite, Inc.

907 W. Outer Drive

Oak Ridge TN 37830

Stephen T. Gonczy

Allied Signal Research

P.O. Box 5016

Des Plaines IL 60017

Robert J. Gottschall

U.S. Department of Energy

ER-131, MS:G-236

Washington DC 20585
Earl Graham

Cleveland State University

Dept. of Chemical Engineering

Euclid Avenue at East 24th St.

Cleveland $\mathrm{OH} 44115$

John W. Graham

Astro Met, Inc.

9974 Springfield Pike

Cincinnati $\mathrm{OH} 45215$

G. A. Graves

U. of Dayton Research Institute

300 College Park

Dayton OH 45469-0001

Robert E. Green, Jr.

Johns Hopkins University

Mater. Sci. and Engineering

Baltimore MD 21218

Alex A. Greiner

Plint \& Partners

Oaklands Park

Wokingham Berkshire RG11 2FD

UNITED KINGDOM

Lance Groseclose

Allison Engine Company

P.O. Box 420, MS:W-5

Indianapolis IN 46206

Thomas J. Gross

U.S. Department of Energy

Transportation Technologies

CE-30, Forrestal Building

Washington DC 20585

Mark F. Gruninger

Union Carbide Corporation

Specialty Powder Business

1555 Main Street

Indianapolis IN 46224

Ernst Gugel

Cremer Forschungsinstitut

GmbH\&Co.KG

Oeslauer Strasse 35

D-8633 Roedental 8633

GERMANY 
John P. Gyekenyesi

NASA Lewis Research Center 21000 Brookpark Road, MS:6-1

Cleveland $\mathrm{OH} 44135$

Nabil S. Hakim

Detroit Diesel Corporation 13400 Outer Drive West

Detroit MI 48239

Philip J. Haley

Allison Engine Company

P.O. Box 420, MS:T12A

Indianapolis IN 46206-0420

Judith Hall

Fiber Materials, Inc.

Biddeford Industrial Park

5 Morin Street

Biddeford ME 04005

Y. Hamano

Kyocera Industrial Ceramics

5713 E. Fourth Plain Blvd.

Vancouver WA 98661-6857

Y. Harada

IIT Research Institute

10 West 35th Street

Chicago IL 60616

Norman H. Harris

Hughes Aircraft Company

P.O. Box 800520

Saugus CA 91380-0520

Alan M. Hart

Dow Chemical Company

1776 Building

Midland MI 48674

Pat E. Hart

Battelle Pacific Northwest Labs

Ceramics and Polymers Development

P.O. Box 999

Richland WA 99352
Michael H. Haselkorn

Caterpillar Inc.

Technical Center, Building E

P.O. Box 1875

Peoria IL 61656-1875

Debbie Haught

U.S. Department of Energy

Off. of Transportation Mater.

EE-34, Forrestal Bldg.

Washington DC 20585

N. B. Havewala

Corning Inc.

SP-PR-11

Corning NY 14831

John Haygarth

Teledyne WAA Chang Albany

P.O. Box 460

Albany OR 97321

Norman L. Hecht

U. of Dayton Research Institute

300 College Park

Dayton OH 45469-0172

Peter W. Heitman

Allison Engine Company

P.O. Box 420, MS:W-5

Indianapolis IN 46206-0420

Robert W. Hendricks

VPI \& SU

210 Holden Hall

Blacksburg VA 24061-0237

Thomas P. Herbell

NASA Lewis Research Center

21000 Brookpark Road, MS:49-3

Cleveland OH 44135

Robert L. Hershey

Science Management Corporation 1255 New Hampshire Ave., N.W.

Suite 1033

Washington DC 20036 
Hendrik Heystek

Bureau of Mines

Tuscaloosa Research Center

P.O. Box L

University AL 35486

Robert V. Hillery

GE Aircraft Engines

One Neumann Way, M.D. H85

Cincinnati OH 45215

Arthur Hindman

Instron Corporation

100 Royall Street

Canton MA 02021

Shinichi Hirano

Mazda R\&D of North America

1203 Woodridge Avenue

Ann Arbor MI 48105

Tommy Hiraoka

NGK Locke, Inc.

1000 Town Center

Southfield MI 48075

Fu H. Ho

5645 Soledad Mtn. Road

San Diego, CA 92037-7256

John M. Hobday

U.S. Department of Energy

Morgantown Energy Tech. Ctr.

P.O. Box 880

Morgantown WV 26507

Clarence Hoenig

Lawrence Livermore National Lab

P.O. Box 808, Mail Code L-369

Livermore CA 94550

Thomas Hollstein

Fraunhofer-Institut fur

Werkstoffmechanik

Wohlerstrasse 11

D-79108 Freiburg

GERMANY
Richard Holt

Natl. Research Council Canada

Structures and Materials Lab

Ottawa Ontario K1A OR6

CANADA

Woodie Howe

Coors Technical Ceramics

1100 Commerce Park Drive

Oak Ridge TN 37830

Stephen M. Hsu

NIST

Gaithersburg MD 20899

Hann S. Huang

Argonne National Laboratory

9700 S. Cass Avenue

Argonne IL 60439-4815

Gene Huber

Precision Ferrites \& Ceramics

5576 Corporate Drive

Cypress CA 90630

Fred R. Huettic

Advanced Magnetics Inc.

45 Corey Lane

Mendham NJ 07945

Brian K. Humphrey

Lubrizol Petroleum Chemicals

3000 Town Center, Suite 1340

Southfield MI 48075-1201

Robert M. Humrick

Dylon Ceramic Technologies

3100 Edgehill Road

Cleveland Heights $\mathrm{OH} 44118$

Michael S. Inoue

Kyocera International, Inc.

8611 Balboa Avenue

San Diego CA 92123-1580

Joseph C. Jackson

U.S. Advanced Ceramics Assoc. 1600 Wilson Blvd., Suite 1008

Arlington VA 22209 
Osama Jadaan

U. of Wisconsin-Platteville

1 University Plaza

Platteville WI 53818

Said Jahanmir

NIST

Materials Bldg., Room A-237

Gaithersburg MD 20899

Curtis A. Johnson

General Electric Company

P.O. Box 8

Schenectady NY 12301

Sylvia Johnson

SRI International

333 Ravenswood Avenue

Menlo Park CA 94025

Thomas A. Johnson

Lanxide Corporation

P.O. Box 6077

Newark DE 19714-6077

Walter F. Jones

AFOSR/NA

110 Duncan Ave., Ste. B115

Washington DC 20332-0001

Jill E. Jonkouski

U.S. Department of Energy

9800 S. Cass Avenue

Argonne IL 60439-4899

L. A. Joo

Great Lakes Research Corporation

P.O. Box 1031

Elizabethton TN 37643

Adam Jostsons

Australian Nuclear Science \&

Technology

New Illawarra Road

Lucas Heightss New South Wales

AUSTRALIA
Lyle R. Kallenbach

Phillips Petroleum

Mail Drop:123AL

Bartlesville OK 74004

Nick Kamiya

Kyocera Industrial Ceramics Corp.

25 NW Point Blvd., \#450

Elk Grove Village IL 60007

Roy Kamo

Adiabatics, Inc.

3385 Commerce Park Drive

Columbus IN 47201

Chih-Chun Kao

Industrial Technology Research

Institute

195 Chung-Hsing Road, Sec. 4

Chutung Hsinchu 31015 R.O.C.

TAIWAN

Keith R. Karasek

AlliedSignal Aerospace Company

50 E. Algonquin Road

Des Plaines IL 60017-5016

Robert E. Kassel

Ceradyne, Inc.

3169 Redhill Avenue

Costa Mesa CA 92626

Allan Katz

Wright Laboratory

Metals and Ceramics Division

Wright-Patterson AFB OH 45433

R. Nathan Katz

Worcester Polytechnic Institute

100 Institute Road

Worcester MA 01609

Ted Kawaguchi

Tokai Carbon America, Inc. 375 Park Avenue, Suite 3802

New York NY 10152 
Noritsugu Kawashima

TOSHIBA Corporation

4-1 Ukishima-Cho

Kawasaki-Ku Kawasaki, 210

JAPAN

Lisa Kempfer

Penton Publishing

1100 Superior Avenue

Cleveland OH 44114-2543

Frederick L. Kennard, III

Delphi Energy \& Engine Mgmt. Systems

Division of General Motors

1300 N. Dort Highway

Flint MI 48556

David O. Kennedy

Lester B. Knight Cast Metals

549 W. Randolph Street

Chicago IL 60661

George Keros

Photon Physics

3175 Penobscot Building

Detroit MI 48226

Thomas Ketcham

Corning, Inc.

SP-DV-1-9

Corning NY 14831

Pramod K. Khandelwal

Allison Engine Company

P.O. Box 420, MS:T10B

Indianapolis IN 46206

Jim R. Kidwell

AlliedSignal Engines

P.O. Box 52180

Phoenix AZ 85072-2180

Shin Kim

The E-Land Group

19-8 ChangJeon-dong

Mapo-gu, Seoul 121-190

KOREA
W. C. King

Mack Truck, Z-41

1999 Pennsylvania Avneue

Hagerstown MD 21740

Carol Kirkpatrick

MSE, Inc.

P.O. Box 3767

Butte MT 59702

Tony Kirn

Caterpillar Inc.

Defense Products Dept., JB7

Peoria IL 61629

James D. Kiser

NASA Lewis Research Center

21000 Brookpark Road, MS:49-3

Cleveland $\mathrm{OH} 44135$

Max Klein

900 24th Street, N.W., Unit G

Washington DC 20037

Richard N. Kleiner

Golden Technologies Company

4545 McIntyre Street

Golden CO 80403

Stanley J. Klima

NASA Lewis Research Center 21000 Brookpark Road, MS:6-1

Cleveland $\mathrm{OH} 44135$

Albert S. Kobayashi

University of Washington

Mechanical Engineering Dept.

Mail Stop:FU10

Seattle WA 98195

Shigeki Kobayashi

Toyota Central Research Labs

Nagakute Aichi, 480-11

JAPAN

Richard A. Kole

Z-Tech Corporation

8 Dow Road

Bow NH 03304 
Joseph A. Kovach

Eaton Corporation

32500 Chardon Road

Willoughby Hills OH 44094

Kenneth A. Kovaly

Technical Insights Inc.

P.O. Box 1304

Fort Lee NJ 07024-9967

Edwin H. Kraft

Kyocera Industrial Ceramics

5713 E. Fourth Plain Boulevard

Vancouver WA 98661

Arthur Kranish

Trends Publishing Inc.

1079 National Press Building

Washington DC 20045

\section{A. S. Krieger}

Radiation Science, Inc.

P.O. Box 293

Belmont MA 02178

Pieter Krijgsman

Ceramic Design International Holding

B.V.

P.O. Box 68

Hattem 8050-AB

THE NETHERLANDS

Waltraud M. Kriven

University of Illinois

105 S. Goodwin Avenue

Urbana IL 61801

Edward J. Kubel, Jr.

ASM International

Advanced Materials \& Processes

Materials Park OH 44073

Dave Kupperman

Argonne National Laboratory

9700 S. Cass Avenue

Argonne IL 60439
Oh-Hun Kwon

North Company

SGNICC/NRDC

Goddard Road

Northboro MA 01532-1545

W. J. Lackey

GTRI

Materials Science and Tech. Lab

Atlanta GA 30332

Jai Lala

Tenmat Ltd.

40 Somers Road

Rugby Warwickshire CV22 7DH

ENGLAND

Hari S. Lamba

General Motors Corporation

9301 West 55th Street

LaGrange IL 60525

Richard L. Landingham

Lawrence Livermore National Lab

P.O. Box 808, L-369

Livermore CA 94550

James Lankford

Southwest Research Institute

6220 Culebra Road

San Antonio TX 78228-0510

Stanley B. Lasday

Business News Publishing Co. 1910 Cochran Road, Suite 630

Pittsburgh PA 15220

S. K. Lau

Carborundum Company

Technology Division

P.O. Box 832, B-100

Niagara Falls NY 14302

J. Lawrence Lauderdale

Babcock \& Wilcox

1525 Wilson Blvd., \#100

Arlington VA 22209-2411 
Jean F. LeCostaouec

Textron Specialty Materials

2 Industrial Avenue

Lowell MA 01851

Benson P. Lee

Technology Management, Inc. 4440 Warrensville Rd., Suite A Cleveland $\mathrm{OH} 44128$

Burtrand I. Lee

Clemson University

Olin Hall

Clemson SC 29634-0907

June-Gunn Lee

KIST

P.O. Box 131, Cheong-Ryang

Seoul $130-650$

KOREA

Stan Levine

NASA Lewis Research Center

21000 Brookpark Road, MS:49-3

Cleveland OH 44135

David Lewis, III

Naval Research Laboratory

Code 6370

Washington DC 20375-5343

Ai-Kang Li

Materials Research Labs., ITRI

195-5 Chung-Hsing Road, Sec. 4

Chutung Hsinchu 31015 R.O.C.

TAIWAN

Robert H. Licht

Norton Company

SGNICC/NRDC

Goddard Road

Northboro MA 01532-1545

E. Lilley

Norton Company

SGNICC/NRDC

Goddard Road

Northboro MA 01532-1545
Chih-Kuang Lin

National Central University

Dept. of Mechanical Engineering

Chung-Li 32054

TAIWAN

Laura J. Lindberg

AlliedSignal Aerospace Company

Garrett Fluid Systems Division

P.O. Box 22200

Tempe AZ 85284-2200

Hans A. Lindner

Cremer Forschungsinstitut

GmbH\&Co.KG

Oeslauer Strasse 35

D-8633 Rodental 8866

GERMANY

Ronald E. Loehman

Sandia National Laboratories

Chemistry \& Ceramics Dept. 1840

P.O. Box 5800

Albuquerque NM 87185

Bill Long

Babcock \& Wilcox

P.O. Box 11165

Lynchburg VA 24506

L. A. Lott

EG\&G Idaho, Inc.

Idaho National Engineering Lab

P.O. Box 1625

Idaho Falls ID 83415-2209

Raouf O. Loutfy

MER Corporation

7960 S. Kolb Road

Tucson AZ 85706

Lydia Luckevich

Ortech International

2395 Speakman Drive

Mississauga Ontario L5K 1B3

CANADA 
James W. MacBeth

Carborundum Company

Structural Ceramics Division

P.O. Box 1054

Niagara Falls NY 14302

George Maczura

Aluminum Company of America

3450 Park Lane Drive

Pittsburgh PA 15275-1119

David Maginnis

Tinker AFB

OC-ALC/LIIRE

Tinker AFB OK 73145-5989

Frank Maginnis

Aspen Research, Inc.

220 Industrial Boulevard

Moore OK 73160

Tai-il Mah

Universal Energy Systems, Inc.

4401 Dayton-Xenia Road

Dayton OH 45432

Kenneth M. Maillar

Barbour Stockwell Company

83 Linskey Way

Cambridge MA 02142

S. G. Malghan

NIST

I-270 \& Clopper Road

Gaithersburg MD 20899

Lars Malmrup

United Turbine $A B$

Box 13027

Malmo S-200 44

SWEDEN

John Mangels

Ceradyne, Inc.

3169 Redhill Avenue

Costa Mesa CA 92626
Murli Manghnani

University of Hawaii

2525 Correa Road

Honolulu HI 96822

Russell V. Mann

Matec Applied Sciences, Inc.

75 South Street

Hopkinton MA 01748

William R. Manning

Champion Aviation Products Div

P.O. Box 686

Liberty SC 29657

Ken Marnoch

Amercom, Inc.

8928 Fullbright Avenue

Chatsworth CA 91311

Robert A. Marra

Aluminum Company of America

Alcoa Technical Center

Alcoa Center PA 15069

Steve C. Martin

Advanced Refractory Technologies

699 Hertel Avenue

Buffalo NY 14207

Kelly J. Mather

William International Corp.

2280 W. Maple Road

Walled Lake MI 48088

James P. Mathers

3M Company

3M Center, Bldg. 201-3N-06

St. Paul MN 55144

Ron Mayville

Arthur D. Little, Inc.

15-163 Acorn Park

Cambridge MA 02140

F. N. Mazadarany

General Electric Company

Bldg. K-1, Room MB-159

P.O. Box 8

Schenectady NY 12301 
James W. McCauley

Alfred University

Binns-Merrill Hall

Alfred NY 14802

Colin F. McDonald

McDonald Thermal Engineering

1730 Castellana Road

La. Jolla CA 92037

B. J. McEntire

Norton Company

10 Airport Park Road

East Granby CT 06026

Chuck McFadden

Coors Ceramics Company

600 9th Street

Golden CO 80401

Thomas D. McGee

Iowa State University

110 Engineering Annex

Ames IA 50011

James McLaughlin

Sundstrand Power Systems

4400 Ruffin Road

P.O. Box 85757

San Diego CA 92186-5757

Matt McMonigle

U.S. Department of Energy

Improved Energy Productivity

CE-231, Forrestal Building

Washington DC 20585

J. C. McVickers

AlliedSignal Engines

P.O. Box 52180, MS:9317-2

Phoenix AZ 85072-2180

D. B. Meadowcroft

"Jura," The Ridgeway

Oxshott

Leatherhead Surrey KT22 OLG

UNITED KINGDOM
Joseph J. Meindl

Reynolds International, Inc.

6603 W. Broad Street

P.O. Box 27002

Richmond VA 23261-7003

Michael D. Meiser

AlliedSignal, Inc.

Ceramic Components

P.O. Box 2960, MS:T21

Torrance CA 90509-2960

George Messenger

National Research Council of Canada

Building M-7

Ottawa Ontario K1A OR6

CANADA

Arthur G. Metcalfe

Arthur G. Metcalfe \& Assoc.

2108 East 24th Street

National City CA 91950

R. Metselaar

Eindhoven University

P.O. Box 513

Endhoven $5600 \mathrm{MB}$

THE NETHERLANDS

David J. Michael

Harbison-Walker Refractories

P.O. Box 98037

Pittsburgh PA 15227

Ken Michaels

Chrysler Motors Corporation

P.O. Box 1118, CIMS:418-17-09

Detroit MI 48288

Bernd Michel

Institute of Mechanics

P.O. Box 408

D-9010 Chemnitz

GERMANY 
D. E. Miles

Commission of the European Community

rue de la Loi 200

B-1049 Brussels

BELGIUM

Carl E. Miller

AC Rochester

1300 N. Dort Highway, MS:32-31

Flint MI 48556

Charles W. Miller, Jr.

Centorr Furnaces/Vacuum

Industries

542 Amherst Street

Nashua NH 03063

R. Minimmi

Enichem America

2000 Cornwall Road

Monmouth Junction NJ 08852

Michele V. Mitchell

AlliedSignal, Inc.

Ceramic Components

P.O. Box 2960, MS:T21

Torrance CA 90509-2960

Howard Mizuhara

WESGO

477 Harbor Boulevard

Belmont CA 94002

Helen Moeller

Babcock \& Wilcox

P.O. Box 11165

Lynchburg VA 24506-1165

Francois R. Mollard

Concurrent Technologies Corp.

1450 Scalp Avenue

Johnstown PA 15904-3374

Phil Mooney

Panametrics

221 Crescent Street

Waltham MA 02254
Geoffrey P. Morris

3M Company

3M Traffic Control Materials

Bldg. 209-BW-10, 3M Center

St. Paul MN 55144-1000

Jay A. Morrison

Rolls-Royce, Inc.

2849 Paces Ferry Rd., Suite 450

Atlanta GA 30339-3769

Joel P. Moskowitz

Ceradyne, Inc.

3169 Redhill Avenue

Costa Mesa CA 92626

Brij Moudgil

University of Florida

Material Science \& Engineering

Gainesville FL 32611

Christoph J. Mueller

Sprechsaal Publishing Group

P.O. Box 2962, Mauer 2

D-8630 Coburg

GERMANY

Thomas W. Mullan

Vapor Technologies Inc.

345 Route 17 South

Upper Saddle River NJ 07458

Theresa A. Mursick-Meyer

Norton Company

SGNICC/NRDC

Goddard Road

Northboro MA 01532-1545

M. K. Murthy

MkM Consultants International

10 Avoca Avenue, Unit 1906

Toronto Onntario M4T 2B7

CANADA

David L. Mustoe

Custom Technical Ceramics

8041 W I-70 Service Rd. Unit 6

Arvada CO 80002 
Curtis V. Nakaishi

U.S. Department of Energy

Morgantown Energy Tech. Ctr.

P.O. Box 880

Morgantown WV 26507-0880

Yoshio Nakamura

Faicera Research Institute

3-11-12 Misono

Sagamihara, Tokyo

JAPAN

K. S. Narasimhan

Hoeganaes Corporation

River Road

Riverton NJ 08077

Robert Naum

Applied Resources, Inc.

P.O. Box 241

Pittsford NY 14534

Malcolm Naylor

Cummins Engine Company, Inc.

P.O. Box 3005, Mail Code 50183

Columbus IN 47202-3005

Fred A. Nichols

Argonne National Laboratory

9700 S. Cass Avenue

Argonne IL 60439

H. Nickel

Forschungszentrum Juelich (KFA)

Postfach 1913

D-52425 Juelich

GERMANY

Dale E. Niesz

Rutgers University

Center for Ceramic Research

P.O. Box 909

Piscataway NJ 08855-0909

Paul W. Niskanen

Lanxide Corporation

P.O. Box 6077

Newark DE 19714-6077
David M. Nissley

United Technologies Corporation

Pratt \& Whitney Aircraft

400 Main Street, MS:163-10

East Hartford CT 06108

Daniel Oblas

50 Meadowbrook Drive

Bedford MA 01730

Don Ohanehi

Magnetic Bearings, Inc.

1908 Sussex Road

Blacksburg VA 24060

Hitoshi Ohmori

ELID Team

Itabashi Branch

1-7 13 Kaga Itabashi

Tokyo 173

JAPAN

Robert Orenstein

General Electric Company

55-112, River Road

Schenectady NY 12345

Richard Palicka

Cercom, Inc.

1960 Watson Way

Vista CA 92083

Joseph N. Panzarino

379 Howard Street

P. O. Box 652

Northboro MA 01532-1545

Pellegrino Papa

Corning Inc.

MP-WX-02-1

Corning NY 14831

Terry Paquet

Boride Products Inc.

2879 Aero Park Drive

Traverse City MI 49684 
E. Beth Pardue

MPC

8297 Williams Ferry Road

Lenior City TN 37771

Soon C. Park

3M Company

Building $142-4 \mathrm{~N}-02$

P.O. Box 2963

St. Paul MN 55144

Vijay M. Parthasarathy

Caterpillar/Solar Turbines

2200 Pacific Highway

P.O. Box 85376

San Diego CA 92186-5376

Harmut Paschke

Schott Glaswerke

Christoph-Dorner-Strasse 29

D-8300 Landshut

GERMANY

James W. Patten

Cummins Engine Company, Inc.

P.O. Box 3005, Mail Code 50183

Columbus IN 47202-3005

Robert A. Penty

Penty \& Associates

38 Oakdale Drive

Rocester NY 14618

Robert W. Pepper

Textron Specialty Materials

2 Industrial Avenue

Lowell MA 01851

Peter Perdue

Detroit Diesel Corporation

13400 Outer Drive West,

Speed Code L-04

Detroit MI 48239-4001

John J. Petrovic

Los Alamos National Laboratory

Group MST-4, MS:G771

Los Alamos NM 87545
Frederick S. Pettit

University of Pittsburgh

Pittsburgh PA 15261

Richard C. Phoenix

Ohmtek, Inc.

2160 Liberty Drive

Niagara Falls NY 14302

Bruce J. Pletka

Michigan Technological Univ.

Metallurgical \& Materials Engr.

Houghton MI 49931

John P. Pollinger

AlliedSignal, Inc.

Ceramic Components

P.O. Box 2960, MS:T21

Torrance CA 90509-2960

P. Popper

High Tech Ceramics Int. Journal 22

Pembroke Drive - Westlands

Newcastle-under-Lyme

Staffs ST5 2JN

ENGLAND

F. Porz

Universitat Karlsruhe

Institut fur Keramik Im

Maschinendau

Postfach 6980

D-76128 Karlsruhe

GERMANY

Harry L. Potma

Royal Netherlands Embassy

Science and Technology

4200 Linnean Avenue, N.W.

Washington DC 20008

Bob R. Powell

General Motors Corporation

Metallurgy Department

Box 9055

Warren MI 48090-9055 
Stephen C. Pred

Biesterfeld U.S., Inc.

500 Fifth Avenue

New York NY 10110

Karl M. Prewo

United Technologies Res. Ctr.

411 Silver Lane, MS:24

East Hartford CT 06108

Vimal K. Pujari

Norton Company

SGNICC/NRDC

Goddard Road

Northboro MA 01532-1545

Fred Quan

Corning Inc.

Sullivan Park, FR-02-08

Corning NY 14831

George Quinn

NIST

Ceramics Division, Bldg. 223

Gaithersburg MD 20899

Ramas V. Raman

Ceracon, Inc.

1101 N. Market Blvd., Suite 9

Sacramento CA 95834

Charles F. Rapp

Owens Corning Fiberglass

2790 Columbus Road

Granville OH 43023-1200

Dennis W. Readey

Colorado School of Mines

Metallurgy and Materials Engr.

Golden CO 80401

Wilfred J. Rebello

PAR Enterprises, Inc.

12601 Clifton Hunt Lane

Clifton VA 22024

Harold Rechter

Chicago Fire Brick Company

7531 S. Ashland Avenue

Chicago IL 60620
Robert R. Reeber

U.S. Army Research Office

P.O. Box 12211

Research Triangle Park NC 27709-2211

K. L. Reifsnider

VPI \& SU

Engineering Science and Mechanics

Blacksburg VA 24061

Paul E. Rempes

McDonnell Douglass Aircraft Co.

P.O. Box 516, Mail Code:0642263

St. Louis MO 63166-0516

Gopal S. Revankar

John Deere Company

3300 River Drive

Moline IL 61265

K. Y. Rhee

Rutgers University

P.O. Box 909

Piscataway NJ 08854

James Rhodes

Advanced Composite Materials

1525 S. Buncombe Road

Greer SC 29651

Roy W. Rice

W. R. Grace and Company

7379 Route 32

Columbia MD 21044

David W. Richerson

2093 E. Delmont Drive

Salt Lake City UT 84117

Tomas Richter

J. H. France Refractories

1944 Clarence Road

Snow Shoe PA 16874 
Michel Rigaud

Ecole Polytechnique

Campus Universite De Montreal

P.O. Box 6079, Station A

Montreal, P.Q. Quebec H3C 3A7

CANADA

John E. Ritter

University of Massachusetts

Mechanical Engineering Department

Amherst MA 01003

W. Eric Roberts

Advanced Ceramic Technology

990 "F" Enterprise Street

Orange CA 92667

Y. G. Roman

TNO TPD Keramick

P.O. Box 595

Einhoven 5600 AN

HOLLAND

Michael Rossetti

Arthur D. Little, Inc.

15 Acorn Park

Cambridge MA 01240

Barry Rossing

Lanxide Corporation

P.O. Box 6077

Newark DE 19714-6077

Steven L. Rotz

Lubrizol Corporation

29400 Lakeland Boulevard

Wickliffe $\mathrm{OH} 44092$

Robert Ruh

Wright Laboratory

WL/MLLM

Wright-Patterson AFB OH 45433

Robert J. Russell

Riverdale Consulting, Inc.

24 Micah Hamlin Road

Centerville MA 02632-2107
Jon A. Salem

NASA Lewis Research Center

21000 Brookpark Road

Cleveland $\mathrm{OH} 44135$

W. A. Sanders

NASA Lewis Research Center 21000 Brookpark Road, MS:49-3

Cleveland $\mathrm{OH} 44135$

J. Sankar

North Carolina A\&T State Univ.

Dept. of Mechanical Engineering

Greensboro NC 27406

Yasushi Sato

NGK Spark Plugs (U.S.A.), Inc. 1200 Business Center Dr., \#300

Mt. Prospect IL 60056

Maxine L. Savitz

AlliedSignal, Inc.

Ceramic Components

P.O. Box 2960, MS:T21

Torrance CA 90509-2960

Ashok Saxena

GTRI

Materials Engineering

Atlanta GA 30332-0245

David W. Scanlon

Instron Corporation

100 Royall Street

Canton MA 02021

Charles A. Schacht

Schacht Consulting Services

12 Holland Road

Pittsburgh PA 15235

Robert E. Schafrik

Natl Materials Advisory Board

2101 Constitution Ave., N.W.

Washington DC 20418

James Schienle

AlliedSignal Engines

P.O. Box 52180, MS:1302-2P

Phoenix AZ 85072-2180 
Gary Schnittgrund

PyroPacific Processes

16401 Knollwood Drive

Granada Hills, CA 91344

Mark Schomp

Lonza, Inc.

17-17 Route 208

Fair Lann NJ 07410

Joop Schoonman

Delft University of Technology

P.O. Box 5045

2600 GA Delft

THE NETHERLANDS

Robert B. Schulz

U.S. Department of Energy

Office of Transportation Mater.

CE-34, Forrestal Building

Washington DC 20585

Murray A. Schwartz

Materials Technology Consulting

30 Orchard Way, North

Potomac MD 20854

Peter Schwarzkopf

SRI International

333 Ravenswood Avenue

Menlo Park CA 94025

William T. Schwessinger

Multi-Arc Scientific Coatings

1064 Chicago Road

Troy MI 48083-4297

W. D. Scott

University of Washington

Materials Science Department

Mail Stop:FB10

Seattle WA 98195

Nancy Scoville

Thermo Electron Technologies

P.O. Box 9046

Waltham MA 02254-9046
Thomas M. Sebestyen

U.S. Department of Energy

Advanced Propulsion Division

CE-322, Forrestal Building

Washington DC 20585

Brian Seegmiller

Coors Ceramics Company

600 9th Street

Golden CO 80401

T. B. Selover

AICRE/DIPPR

3575 Traver Road

Shaker Heights $\mathrm{OH} 44122$

Charles E. Semler

Semler Materials Services

4160 Mumford Court

Columbus $\mathrm{OH} 43220$

Thomas Service

Service Engineering Laboratory

324 Wells Street

Greenfield MA 01301

Kish Seth

Ethyl Corporation

P.O. Box 341

Baton Rouge LA 70821

William J. Shack

Argonne National Laboratory

9700 S. Cass Avenue, Bldg. 212

Argonne IL 60439

Peter T.B. Shaffer

Shaffer Associates

3225 Chimney Cove Drive

Cumming GA 30131

Richard K. Shaltens

NASA Lewis Research Center

21000 Brookpark Road, MS:302-2

Cleveland $\mathrm{OH} 44135$

Robert S. Shane

1904 NW 22nd Street

Stuart FL 34994-9270 
Ravi Shankar

Chromalloy

Research and Technology

Blaisdell Road

Orangeburg NY 10962

Terence Sheehan

Alpex Wheel Company

727 Berkley Street

New Milford NJ 07646

Dinesh K. Shetty

University of Utah

Materials Science and Engineering

Salt Lake City UT 84112

Masahide Shimizu

New Ceramics Association

Shirasagi 2-13-1-208, Nakano-ku

Tokyo, 165

JAPAN

Thomas Shreves

American Ceramic Society, Inc.

735 Ceramic Place

Westerville $\mathrm{OH} 43081-8720$

Jack D. Sibold

Coors Ceramics Company

4545 McIntyre Street

Golden CO 80403

Johann Siebels

Volkswagen AG

Werkstofftechnologie

Postfach 3180

Wolfsburg 1

GERMANY

George H. Siegel

Point North Associates, Inc.

P.O. Box 907

Madison NJ 07940

Richard Silberglitt

FM Technologies, Inc.

10529-B Braddock Road

Fairfax VA 22032
Mary Silverberg

Norton Company

SGNICC/NRDC

Goddard Road

Northboro MA 01532-1545

Gurpreet Singh

Department of the Navy

Code 56X31

Washington DC 20362-5101

Maurice J. Sinnott

University of Michigan

5106 IST Building

Ann Arbor MI 48109-2099

John Skildum

3M Company

3M Center

Building 224-2S-25

St. Paul MN 55144

Richard H. Smoak

Smoak \& Associates

3554 Hollyslope Road

Altadena CA 91001-3923

Jay R. Smyth

AlliedSignal Engines

111 S. 34th Street, MS:503-412

Phoenix AZ 85034

Rafal A. Sobotowski

British Petroleum Company

Technical Center, Broadway

3092 Broadway Avenue

Cleveland $\mathrm{OH} 44115$

S. Somiya

Nishi Tokyo University

3-7-19 Seijo, Setagaya

Tokyo, 157

JAPAN

Boyd W. Sorenson

DuPont Lanxide Composites

1300 Marrows Road

Newark DE 19711 
Charles A. Sorrell

U.S. Department of Energy

Advanced Industrial Concepts

CE-232, Forrestal Building

Washington DC 20585

C. Spencer

EA Technology

Capenhurst Chester CH1 6ES

UNITED KINGDOM

Allen Spizzo

Hercules Inc.

Hercules Plaza

Wilmington DE 19894

Richard M. Spriggs

Alfred University

Ctr. for Advanced Ceramic Tech.

Alfred NY 14802

Charles Spuckler

NASA Lewis Research Center

21000 Brookpark Road, MS:5-11

Cleveland OH 44135-3191

Gordon L. Starr

Cummins Engine Company, Inc.

P.O. Box 3005, Mail Code:50182

Columbus IN 47202-3005

Tom Stillwagon

AlliedSignal, Inc.

Ceramic Components

P.O. Box 2960, MS:T21

Torrance CA 90509-2960

H. M. Stoller

TPL Inc.

3754 Hawkins, N.E.

Albuquerque NM 87109

Paul D. Stone

Dow Chemical USA

1776 "Eye" Street, N.W., \#575

Washington DC 20006
F. W. Stringer

Aero \& Industrial Technology

P.O. Box 46, Wood Top

Burnley Lancashire BB11 4BX

UNITED KINGDOM

Thomas N. Strom

NASA Lewis Research Center

21000 Brookpark Road, MS:86-6

Cleveland $\mathrm{OH} 44135$

M. F. Stroosnijder

Institute for Advanced Materials

Joint Research Centre

21020 Ispra (VA)

ITALY

Karsten Styhr

30604 Ganado Drive

Rancho Palos Verdes CA 90274

T. S. Sudarshan

Materials Modification, Inc.

2929-P1 Eskridge Center

Fairfax VA 22031

M. J. Sundaresan

University of Miami

P.O. Box 248294

Coral Gables FL 33124

Patrick L. Sutton

U.S. Department of Energy

Office of Propulsion Systems

CE-322, Forrestal Building

Washington DC 20585

Willard H. Sutton

United Technologies Corporation

Silver Lane, MS:24

East Hartford CT 06108

Robert E. Swanson

Metalworking Technology, Inc.

1450 Scalp Avenue

Johnstown PA 15904 
Yo Tajima

NGK Spark Plug Company

2808 Iwasaki

Komaki-shi Aichi-ken, 485

JAPAN

Fred Teeter

5 Tralee Terrace

East Amherst NY 14051

Victor J. Tennery

113 Newell Lane

Oak Ridge TN 37830

Monika O. Ten Eyck

Carborundum Microelectronics

P.O. Box 2467

Niagara Falls NY 14302-2467

David F. Thompson

Corning Glass Works

SP-DV-02-1

Corning NY 14831

T. Y. Tien

University of Michigan

Materials Science \& Engineering

Dow Building

Ann Arbor MI 48103

D. M. Tracey

Norton Company

SGNICC/NRDC

Goddard Road

Northboro MA 01532-1545

Marc Tricard

Norton Company, WGTC

1 New Bond Street, MS-413-201

Worcester MA 01615-0008

L. J. Trostel, Jr.

Box 199

Princeton MA 01541

W. T. Tucker

General Electric Company

P.O. Box 8, Bldg. K1-4C35

Schenectady NY 12301
Masanori Ueki

Nippon Steel Corporation

1618 Ida

Nakahara-Ku Kawasaki, 211

JAPAN

Filippo M. Ugolini

ATA Studio

Via Degli Scipioni, 268A

ROMA, 00192

ITALY

Donald L. Vaccari

Allison Gas Turbines

P.O. Box 420, Speed Code S49

Indianapolis IN 46206-0420

Carl F. Van Conant

Boride Products, Inc.

2879 Aero Park Drive

Traverse City MI 49684

John F. Vander Louw

3M Company

3M Center, Bldg. 60-1N-01

Saint Paul MN 55144

Marcel H. Van De Voorde

Commission of the European

Community

P.O. Box 2

1755 ZG Petten

THE NETHERLANDS

O. Van Der Biest

Katholieke Universiteit Leuven

Dept. Metaalkunde en Toegepaste

de Croylaan 2

B-3030 Leuven

BELGIUM

Michael Vannier

Washington University,

St. Louis

510 S. Kings Highway

St. Louis MO 63110 
Stan Venkatesan

Southern Coke \& Coal Corp.

P.O. Box 52383

Knoxville TN 37950

V. Venkateswaran

Carborundum Company

Niagara Falls R\&D Center

P.O. Box 832

Niagara Falls NY 14302

Ted Vojnovich

U.S. Department of Energy

Office of Energy Research, 3F077P

Washington DC 20585

John D. Volt

E.I. Dupont de Nemours \& Co.

P.O. Box 80262

Wilmington DE 19880

John B. Wachtman

Rutgers University

P.O. Box 909

Piscataway NJ 08855

Shigetaka Wada

Toyota Central Research Labs

Nagakute Aichi, 480-11

JAPAN

Janet Wade

AlliedSignal Engines

P.O. Box 52180, MS:1303-2

Phoenix AZ 85072-2180

Richard L. Wagner

Ceramic Technologies, Inc.

537 Turtle Creek South Dr.

Indianapolis IN 46227

J. Bruce Wagner, Jr.

Arizona State University

Center for Solid State Science

Tempe AZ 85287-1704

Daniel J. Wahlen

Kohler, Co.

444 Highland Drive

Kohler WI 53044
Ingrid Wahlgren

Royal Institute of Technology

Studsvik Library

S-611 82 Nykoping

SWEDEN

Ron H. Walecki

AlliedSignal, Inc.

Ceramic Components

P.O. Box 2960, MS:T21

Torrance CA $90509-2960$

Michael S. Walsh

Vapor Technologies Inc.

6300 Gunpark Drive

Boulder CO 80301

Chien-Min Wang

Industrial Technology Research

Institute

195 Chung-Hsing Road, Sec. 4 Chutung Hsinchu 31015 R.O.C.

TAIWAN

Robert M. Washburn

ASMT

11203 Colima Road

Whittier CA 90604

Kevin Webber

Toyota Technical Center, U.S.A.

1410 Woodridge, RR7

Ann Arbor MI 48105

Karen E. Weber

Detroit Diesel Corporation

13400 Outer Drive West

Detroit MI 48239-4001

James K. Weddell

Du Pont Lanxide Composites Inc.

P.O. Box 6100

Newark DE 19714-6100

R. W. Weeks

Argonne National Laboratory

MCT-212

9700 S. Cass Avenue

Argonne IL 60439 
Ludwig Weiler

ASEA Brown Boveri AG

Eppelheimer Str. 82

D-6900 Heidelberg

GERMANY

James Wessel

127 Westview Lane

Oak Ridge TN 37830

Robert D. West

Therm Advanced Ceramics

P.O. Box 220

Ithaca NY 14851

Thomas J. Whalen

1845 Cypress Pointe Court

Ann Arbor MI 48108

Ian A. White

Hoeganaes Corporation

River Road

Riverton NJ 08077

Sheldon M. Wiederhorn

NIST

Building 223, Room A329

Gaithersburg MD 20899

John F. Wight

Alfred University

McMahon Building

Alfred NY 14802

D. S. Wilkinson

McMaster University

1280 Main Street, West

Hamilton Ontario L8S 4L7

CANADA

James C. Williams

General Electric Company

Engineering Materials Tech.

One Neumann Way, Mail Drop:H85

Cincinnati OH 45215-6301

Steve J. Williams

RCG Hagler Bailly, Inc.

1530 Wilson Blvd., Suite 900

Arlington VA 22209-2406
Thomas A. Williams

National Renewable Energy Lab

1617 Cole Boulevard

Golden CO 80401

Craig A. Willkens

Norton Company

SGNICC/NRDC

Goddard Road

Northboro MA 01532-1545

Roger R. Wills

Ohio Aerospace Institute (OAI)

22800 Cedar Point Road

Brook Park OH 44142

David Gordon Wilson

Massachusetts Institute of

Technology

77 Massachusetts Ave., Rm 3-455

Cambridge MA 02139

J. M. Wimmer

AlliedSignal Ceramic Components

Department 27000, MS:T21

2525 W. 190th Street

Torrance CA 90509

Matthew F. Winkler

Seaworthy Systems, Inc.

P.O. Box 965

Essex CT 06426

Gerhard Winter

Hermann C. Starck Berlin GmbH

P.O. Box 25.40

D-3380 Goslar 3380

GERMANY

Thomas J. Wissing

Eaton Corporation

Engineering and Research Center

P.O. Box 766

Southfield MI 48037

James C. Withers

MER Corporation

7960 S. Kolb Road

Building $F$

Tucson AZ 85706 
Dale E. Wittmer

Southern Illinois University

Mechanical Engineering Dept.

Carbondale IL 62901

Warren W. Wolf

Owens Corning Fiberglass

2790 Columbus Road, Route 16

Granville OH 43023

Egon E. Wolff

Caterpillar Inc.

Technical Center

P.O. Box 1875

Peoria IL 61656-1875

George W. Wolter

Howmet Turbine Components Corp.

Technical Center

699 Benston Road

Whitehall MI 49461

Wayne L. Worrell

University of Pennsylvania

3231 Walnut Street

Philadelphia PA 19104

John F. Wosinski

Corning Inc.

ME-2 E-5 H8

Corning NY 14830

Ruth Wroe

ERDC

Capenhurst Chester CH1 6ES

ENGLAND

Bernard J. Wrona

Advanced Composite Materials

1525 S. Buncombe Road

Greer. SC 29651

Carl C. M. Wu

Naval Research Laboratory

Ceramic Branch, Code 6373

Washington DC 20375
David C. Wu

AlliedSignal Engines

P.O. Box 52181, MS:301-227

Phoenix AZ 85072-2181

John C. Wurst

U. of Dayton Research Institute

300 College Park

Dayton OH 45469-0101

Neil Wyant

ARCH Development Corp.

9700 S. Cass Avenue, Bldg. 202

Argonne IL 60439

Roy Yamamoto

Texaco Inc.

P.O. Box 509

Beacon NY 12508-0509

John Yamanis

AlliedSignal Aerospace Company

P.O. Box 1021

Morristown NJ 07962-1021

Harry C. Yeh

AlliedSignal, Inc.

Ceramic Components

P.O. Box 2960, MS:T21

Torrance CA $90509-2960$

Hiroshi Yokoyama

Hitachi Research Lab

4026 Kuji-Cho

Hitachi-shi Ibaraki 319-12

JAPAN

Thomas M. Yonushonis

Cummins Engine Company, Inc.

P.O. Box 3005, Mail Code 50183

Columbus IN 47202-3005

Jong Yung

Sundstrand Aviation Operations

4747 Harrison Avenue

Rockford IL 61125

C. S. Yust

106 Newcrest Lane

Oak Ridge TN 37830 
A. L. Zadoks

Caterpillar Inc.

Technical Center, Building L

P.O. Box 1875

Peoria IL 61656-1875

Avi Zangvil

University of Illinois

104 S. Goodwin Avenue

Urbana IL 61801

Charles H. Zenuk

Transtech

6662 E. Paseo San Andres

Tucson AZ 85710-2106

Carl Zweben

General Electric Company

P. O Box 8555, VFSC/V4019

Philadelphia PA 19101

Department of Energy

Oak Ridge Operations Office

Asst. Manager for Energy

Research and Development

P.O. Box 2001

Oak Ridge, TN 37871-8600

Department of Energy

Office of Scientific and

Technical Information

Office of Information Services

P.O. Box 62

Oak Ridge, TN 37831 ? 
